NBER WORKING PAPER SERIES

\title{
CHINA'S WAR ON POLLUTION: EVIDENCE FROM THE FIRST FIVE YEARS
}

\author{
Michael Greenstone \\ Guojun $\mathrm{He}$ \\ Shanjun Li \\ Eric Zou \\ Working Paper 28467 \\ http://www.nber.org/papers/w28467 \\ NATIONAL BUREAU OF ECONOMIC RESEARCH \\ 1050 Massachusetts Avenue \\ Cambridge, MA 02138 \\ February 2021
}

The authors thank Claire Fan, Wenzheng Li, Yuhang Pan, and Luming Tan for excellent research assistance, Yazhen Gong for generous data sharing, and Cynthia Lin Lawell for comments. Financial support from the Center for Industrial Development and Environmental Governance (CIDEG) of Tsinghua University is greatly appreciated. The authors have no relevant and material financial relationships to disclose. The views expressed herein are those of the authors and do not necessarily reflect the views of the National Bureau of Economic Research.

NBER working papers are circulated for discussion and comment purposes. They have not been peer-reviewed or been subject to the review by the NBER Board of Directors that accompanies official NBER publications.

(C) 2021 by Michael Greenstone, Guojun He, Shanjun Li, and Eric Zou. All rights reserved. Short sections of text, not to exceed two paragraphs, may be quoted without explicit permission provided that full credit, including $\odot$ notice, is given to the source. 
China's War on Pollution: Evidence from the First Five Years

Michael Greenstone, Guojun He, Shanjun Li, and Eric Zou

NBER Working Paper No. 28467

February 2021

JEL No. Q50,Q53,Q56

\section{ABSTRACT}

The decade from 2010 to 2019 marked a significant turning point in China's history of environmental regulation and pollution. This article describes the recent trends in air and water quality, with a focus on the five years since China declared a "war on pollution" in 2014. It summarizes the emerging literature that has taken advantage of accompanying improvements in data availability and accuracy to document sharp improvements in environmental quality, especially local air pollution, and understand their social, economic, and health consequences.

Michael Greenstone

University of Chicago

Department of Economics

1126 E. 59th Street

Chicago, IL 60637

and NBER

mgreenst@uchicago.edu

Guojun $\mathrm{He}$

Division of Social Science

HKUST, Clear Water Bay

Kowloon

Hong Kong

guojun.he@gmail.com
Shanjun Li

Cornell University

405 Warren Hall

Ithaca, NY 14853

and NBER

SL2448@cornell.edu

Eric Zou

Department of Economics

University of Oregon

1415 Kincaid Street

Eugene, OR 97403

and NBER

ericzou@uoregon.edu 


\section{Introductions}

China's unprecedented economic growth, heavy reliance on fossil fuel, and lax environmental regulations have significantly degraded the country's environmental quality. By the end of the first decade of the 2000s, China had become the world's largest consumer of energy and coal, the largest automobile market, and the largest emitter of $\mathrm{CO}_{2}$ and $\mathrm{SO}_{2}$. Dubbed "airpocalypse" by international news media, severe smog episodes in large urban centers such as Beijing outraged the Chinese public. Outcry emerged over the lack of basic, public provision of pollution information and the absence of effective government responses to address the situation.

Against such a backdrop, China began to shift away from its long-standing strategy of prioritizing economic growth over environmental concerns. In March 2014, Premier Li Keqiang declared a "war on pollution" at the opening of the annual meeting of People's Congress 2014, denouncing smog as "nature's warning against inefficient and blind development." In response, the government undertook unprecedented regulatory changes on multiple fronts. These changes included: (1) recognizing $\mathrm{PM}_{2.5}$ as a primary pollutant and establishing national maximum standards for $\mathrm{PM}_{2.5}$ for the first time; (2) setting pollution reduction as one of the bureaucratic hard targets in government officials' evaluation and promotion; (3) launching a nationwide, realtime air quality monitoring and disclosure program; and (4) implementing a range of environmental policies, including piloting seven regional $\mathrm{CO}_{2}$ cap-and-trade programs and promoting the electrification of the passenger transportation system.

Since 2014, China has been making significant progress in improving air quality. Local air pollution levels have fallen significantly: five years after the peak in 2013 , national-level $\mathrm{PM}_{2.5}$ levels declined by about 40 percent, and $\mathrm{SO}_{2}$ and $\mathrm{CO}$ concentrations fell by 65 percent and 33 percent, respectively. In comparison, the United States took at least a decade and two significant recessions to achieve comparable percentage reductions in air pollution following the Clean Air Act's passage. ${ }^{2}$ That being said, the air pollution levels in China remain high, suggesting further efforts are necessary to bring the country's environmental quality in line with international recommendations. The national average $\mathrm{PM}_{2.5}$ concentration in 2018 , for example, was 40.1 $\mu \mathrm{g} / \mathrm{m}^{3}$, which is still more than 4 times higher than what is considered safe by the World Health Organization (WHO) $\left(10 \mu \mathrm{g} / \mathrm{m}^{3}\right.$ for the annual mean).

This paper summarizes the emerging literature that has taken advantage of the improvements in data availability and accuracy to understand the economic, social, and health consequences of China's "war on pollution." We start by describing recent trends in local air (i.e., criteria pollutants, not $\mathrm{CO}_{2}$ ) and water pollution in China, then review empirical evidence on the pollution impact in the past decade and conclude with a discussion of future research. ${ }^{3}$ Two recent articles by Karplus et al. (2020), and Auffhammer et al. (2020) offer complementary reviews on the role of environmental regulations and the development of renewable energy in China to address the pressing environmental and energy challenges.

\footnotetext{
${ }^{2}$ For pollution reduction in the US under the Clean Air Act, see https://www.epa.gov/air-trends.

${ }^{3}$ Vennemo et al. (2009) and Zheng and Kahn (2013) provide earlier reviews of research on the causes and consequences of China's environmental challenges, with the former focusing on the status and trends, and the latter focusing on the role of urbanization and the regulatory environment.
} 


\section{Recent Trends on Environmental Quality}

\subsection{Air Quality}

Data. We use publicly available air quality data from the real-time monitoring and reporting system of China's Ministry of Ecology and Environment (MEE, formerly the Ministry of Environmental Protection). From 2013 to 2015, China rolled out a new, nationwide air pollution program in three waves across cities to provide real-time monitoring and reporting of six air pollutants, including $\mathrm{PM}_{2.5}, \mathrm{PM}_{10}, \mathrm{O}_{3}, \mathrm{CO}, \mathrm{NO}_{2}$, and $\mathrm{SO}_{2}$. Hourly real-time pollution readings are available from about 1,600 monitoring sites spread across almost every city, covering $98 \%$ of the total population. Due to concerns on the accuracy and reliability of the prior monitoring system (see discussion below), we restrict the analysis to this more recent data. To accurately illustrate trends, we adjust the unbalanced city-level panel data sets for differences in average pollution levels across cities that began monitoring at different times. Because the government monitoring data are available only for recent years, we complement these data with satellitebased $\mathrm{PM}_{2.5}$ estimates from 1998 to 2018 (van Donkelaar et al., 2019).

Trends. We begin with city-day-level air pollution data, and we use the following equation to estimate year-to-year changes in air quality:

$$
\text { Pollution }_{\text {ict }}=\sum_{\tau=2013}^{2018} \beta_{i \tau} 1(y=\tau)+\alpha_{i c}+\varepsilon_{i c t}
$$

where the dependent variable is the concentration of air pollutant $i$ in city $c$ on date $t .{ }^{4}$ Because the initiation of real-time monitoring varies across cities, we include pollutant by city fixed effects $\left(\alpha_{i c}\right)$ to account for level differences in average pollution levels across cities in the unbalanced panel. Intuitively, the $\beta_{i \tau}$ 's reveal the changes in annual levels in each pollutant using variation within city and over time. As the $i$ subscript indicates, equation (1) is estimated separately for each air pollutant.

Panel (a) in Figure 1 plots the year-by-year coefficient estimates $\left(\beta_{\tau}{ }^{\prime} s\right)$ for six pollutants. For comparison, we scale the concentration of each pollutant so that it equals 100 in $2013 .{ }^{5}$ All of the air pollutant concentrations dropped sharply since 2013, except for $\mathrm{O}_{3}$, which saw a modest increase. $\mathrm{PM}_{2.5}$ levels dropped by $27.7 \mu \mathrm{g} / \mathrm{m}^{3}$, or about 41 percent from the 2013 level. $\mathrm{SO}_{2}$ concentrations fell the most, declining by over 65 percent. $\mathrm{O}_{3}$ concentration increased by 8.5 percent from 2013 to 2018, highlighting the complex nature of $\mathrm{O}_{3}$ formation and the resulting challenge to contain it in the face of continued urbanization and motorization. ${ }^{6}$ Appendix Figure

\footnotetext{
${ }^{4}$ When there are multiple monitors operating in the city-day, we take the average across the readings from these monitors. We have confirmed that the trend estimates are similar if we conduct analysis using monitor-level data (and controlling for monitor fixed effects).

${ }^{5}$ We pick 2013 as it was the first year when real-time monitoring became available in China. Our satellite data (Figure A.1 and Figure A.3) suggest the average $\mathrm{PM}_{2.5}$ concentration in 2013 is similar to the levels in 2010-2012. ${ }^{6} \mathrm{O}_{3}$ is not directly emitted; it is produced by photochemical reactions between $\mathrm{NO}_{\mathrm{x}}$ and volatile organic compounds (VOCs) via a nonlinear and non-monotonic relationship in the presence of sunlight (Sillman 1999). Thus, when VOCs are limited, a decrease in $\mathrm{NO}_{\mathrm{x}}$ emissions could increase $\mathrm{O}_{3}$, as empirically documented by Salvo and Geiger (2014), and Zhang et al. (2017) in São Paulo and Bogotá, respectively. The VOC-limited photochemical regime could be caused by the larger reductions in VOCs than in NOx during our sample period.
} 
1 shows the national annual average concentration levels of each of the six pollutants. Overall, the evidence suggests that China achieved large reductions in air pollution in just five years.

Earlier studies suggest that China's official air quality data was manipulated in some instances (e.g., Andrews, 2008; Chen et al., 2012; Ghanem and Zhang, 2014). The more recent data is less likely to be manipulated due to the upgraded monitoring system that automates the sampling and reporting process, greatly reducing the scope for tampering (Greenstone et al., 2020). Importantly, we examine satellite-based pollution estimates in Appendix Figure 1 and find that air pollution levels in China have substantially declined in these data too. Besides, Appendix Figure 3 suggests that the real-time $\mathrm{PM}_{2.5}$ data from MEE are consistent with those from independent monitoring by the U.S. embassy and consulates in Beijing, Chengdu, Guangzhou, Shanghai, and Shenyang. The satellite $\mathrm{PM}_{2.5}$ data are calibrated using ground monitor data and the measure is thus not an entirely independent benchmark. In Appendix Figure 4, we report that direct satellite observations of aerosol optical depth - a key impute of satellite-derived $\mathrm{PM}_{2.5}$ measure - also show a consistently downward trend since 2010. Overall, the readings from the new monitoring system correspond well with independent measures, confirming the improvement in air quality.

To quantify the mortality benefit of the observed reduction in $\mathrm{PM}_{2.5}$ concentration, we use the Air Quality Life Index (AQLI), which measures the potential gain in life expectancy from pollution reduction. ${ }^{7}$ The index is based on work by Ebenstein et al. (2017), who estimate the causal effect of sustained exposure to particulate pollution on life expectancy in China. Holding everything else equal, the AQLI predicts that a permanent reduction of $\mathrm{PM}_{2.5}$ from the 2013 to 2018 level would generate a remarkable gain in average life expectancy of 2.7 years per person.

Spatial Heterogeneity. We examine regional heterogeneity in air quality trends by estimating equation (1) separately for each of the six regions of China. Panel (b) in Figure 2 shows that, although the speed of the initial clean up differed across regions, all six regions experienced similar $\mathrm{PM}_{2.5}$ reduction in percentage terms by the end of 2018 .

To further explore regional differences in $\mathrm{PM}_{2.5}$ reductions, we estimate a linear trend in $\mathrm{PM}_{2.5}$ for each city using the monitoring data from 2015 when all cities had begun real-time air quality monitoring. We plot the city-specific coefficient estimates in Appendix Figure 5. Panel (a) shows the average annual changes between 2015 and 2018 in $\mathrm{PM}_{2.5}$ by city, and panel (b) shows the percentage changes. We observe a striking $\mathrm{PM}_{2.5}$ decline in many cities of the country, including the area around Beijing, parts of the northeast, and parts of the west. Notably, the area around Beijing, one of the focal points of China's cleaning-up efforts, experienced a reduction of over $12 \mu \mathrm{g} / \mathrm{m}^{3}$ per year during 2015-2018. We predict that, back in 2013, only 20 percent of Chinese cities (13 percent of the population) were in compliance with the government's 2012 ambient $\mathrm{PM}_{2.5}$ annual standard of $35 \mu \mathrm{g} / \mathrm{m}^{3}$. In 2018, about 41 percent of the cities (29 percent of the population) met the standard. There is substantial heterogeneity in the magnitude of air quality improvements across different cities. While air quality improvement occurred almost across the entire nation, a handful of places, such as Linfen in Shanxi Province and Chizhou in Anhui province, experienced consistent increases in $\mathrm{PM}_{2.5}$.

\footnotetext{
${ }^{7} \mathrm{AQLI}$ is developed to measure and communicate the health risks posed by particulate matter air pollution around the world. More information can be found at: https://aqli.epic.uchicago.edu.
} 
The rich spatial pattern shown in Appendix Figure 5 raises the question of why air quality improved much faster in certain cities than in others. While it is beyond the scope of this paper to examine the causes underlying the spatial heterogeneity, we document several correlates of air quality improvement. Appendix Figures 6 and 7 report coefficient estimates from a crosssectional regression of the $\mathrm{PM}_{2.5}$ reduction per year in level and in percentage, respectively, on city-level demographic and industrial characteristics during the 2011-2012 (baseline) period. We find that air quality improved more quickly during the 2015-2018 period in cities that were larger in population size and wealthier, as measured by GDP per capita. In addition, cities that had high concentrations of certain industries - such as the stone, clay, and glass-product manufacturing sectors - showed significantly larger pollution reductions. Cities with more coal mining activities and the waste recycling industry were less likely to experience such reductions.

These correlations are not necessarily causal, and understanding the precise causes of the pollution reductions warrants further research. We only note that there have been a wide variety of policies that target air pollution and energy consumption, and sorting out the causal impacts of individual ones would be of great academic and policy interest. The impacts and effectiveness of these policies are the focus of Karplus et al. (2020) and Auffhammer et al. (2020) in the symposium.

\subsection{Water Quality}

Data. We use publicly available data from the MEE's Major River Basins Water Quality Reports, which contain weekly surface water quality data from about 110 monitoring stations. Panel (a) of Appendix Figure 8 shows the location of the monitors. These monitors cover major river basins in China and reflect surface water quality in river segments that are deemed important by the MEE. ${ }^{8}$ We use water quality data from 2008 to 2018 . Prior to 2008, there was no systematic realtime water quality reporting.

Trends. Due to the small number of monitoring sites in the reports, we summarize water quality for monitors in river basins, including those of the Yellow, Yangtze, Huai rivers. We aggregate the original station-weekly-level data to compute year-to-year changes. Figure 2 shows two measures of water quality: dissolved oxygen (DO in $\mathrm{mg} / \mathrm{L}$ ) concentration - the degree of the water's oxygen saturation, and thus a measure of suitability for aquatic lives; and chemical oxygen demand (COD in $\mathrm{mg} / \mathrm{L}$ ) - the degree of oxygen depletion in the water as a result of bacteria actions, and thus a measure of water pollution. Appendix Figure 8, Panel (b) plots the third measure of water quality: the fraction of Grade I, II, and III water- "swimmable" water. 9

\footnotetext{
${ }^{8}$ Admittedly, the water quality data we collect are not representative to the entire country's water pollution, as smaller rivers and lakes are generally more polluted. Unfortunately, water quality data from these less important monitoring stations are not systematically published by the MEE. This partially explains why there are fewer studies on water pollution. Over the past three decades, the MEE has significantly expanded the national water quality monitoring system: by 2015 , there were 972 national water quality monitoring stations across China, and the number is expected to increase to more than 2,700 stations by 2020 .

${ }^{9}$ These measures have been used in previous research of water quality both in China and in the US (e.g., Greenstone and Hanna, 2014; Kahn et al., 2015; Keiser, et al., 2019; Keiser and Shapiro, 2019; He et al., 2020).
} 
These figures reveal two key patterns. First, water quality steadily improved from 2008 to 2018 in all regions except the Yangtze River Basin, which has the best initial water quality. ${ }^{10}$ Second, there is a visible trend of convergence that water quality in all rivers becomes similar. The water quality improvement is the largest in the Huai River Yellow River basins, which initially had the worst water quality.

Publicly available data on drinking water and groundwater quality (which are distinct from surface water quality) are too limited to allow for similar analyses. However, based on the various annual reports of the MEE, we plot groundwater quality in Appendix Figure 9 and find that it deteriorated from 2010 to $2017 .{ }^{11}$ The striking difference between the surface water and groundwater is likely due to the weaker regulations on groundwater. Groundwater pollution is less visible than surface water pollution and technically more challenging to address.

\section{The Impacts of Pollution on Human Well-Being}

Given the magnitude of its pollution challenges, the rapidly changing policy environment, and the rich set of environmental measures deployed, China provides a unique and rich setting for studying pollution's impacts on human well-being. Here, we review this emerging literature, which can complement the rich literature from developed countries. Because developing countries differ from developed countries along many dimensions (including regulatory environments, access to health care, and initial levels of pollution and population health), it is possible that the pollution impacts in developing countries are also different (Arceo et al. 2016; Greenstone and Jack 2015). ${ }^{12}$ This review focuses primarily on the more mature literature on air pollution, but we also include a section summarizing the findings on water pollution.

\subsection{Empirical Framework and Identification Strategy}

We first discuss the empirical framework and the key identification strategies commonly used in the literature. A linear equation in a panel-data setting is often used, with the dependent variable being the outcome of interest (e.g., mortality rate) and the key variable of interest being a measure of ambient pollution level:

$$
y_{i t}=x_{i t} \beta+\alpha \text { Pollution }_{i t}+\epsilon_{i t}
$$

where $i$ denotes a region and $t$ denotes time. The key challenge in estimating the causal impact of pollution on health (and on many other outcomes) is that variation in pollution could be endogenous. Take air pollution as an example. Air pollution levels are often influenced by complex meteorological processes that can directly affect human health, yet it is difficult to

\footnotetext{
${ }^{10}$ The average DO levels at the monitored locations are around $7.5 \mathrm{mg} / \mathrm{L}$. This exceeds the U.S. EPA's recommended 30-day minimum concentration of $6.5 \mathrm{mg} / \mathrm{L}$ for aquatic life.

${ }^{11}$ The reports can be accessed via http://www.mee.gov.cn/hjzl/zghjzkgb/lnzghjzkgb/. Note that the groundwater quality standards are different from surface water quality standards, even though both use a grade system to define different levels of water pollution.

${ }^{12}$ Please refer to Graff Zivin and Neidell (2013) and Currie et al. (2014) for reviews on studies focusing on U.S. and other countries.
} 
control for all these factors in the research. In addition, other unobservable social and economic factors (e.g., income) could be correlated with both air pollution and the outcome variables.

The economic literature has mostly relied on quasi-experimental designs to credibly estimate the causal impact of air pollution (Greenstone and Gayer, 2009). In these designs, researchers typically leverage changes in meteorological conditions, regulations, and specific events/shocks to isolate the pollution impacts from the confounding factors.

Several studies explore changes in meteorological conditions (wind, thermal inversion, etc.) to estimate the impact of air pollution. For example, wind can disperse pollutants and exogenously change local air pollution levels. Under the assumption that unobservables from upwind areas (of a certain distance) from a given location are not correlated with local unobservable determinants of the outcome, wind direction is often used to generate valid instrumental variables (IVs). Thermal inversion is another common IV in the literature (e.g., Arceo et al., 2016). Thermal inversion occurs when warm air settles over cooler air. When it occurs, air pollutants will be trapped from rising and dispersing. It is like putting a lid on a pot and can significantly increase ground-level air pollution concentrations.

Another source for identification comes from policy changes that in principle affect the outcome variables only through their impacts on air pollution. Notable examples include those on the impacts of the Clean Air Act in the U.S. (e.g., Chay and Greenstone, 2005; Deschenes et al., 2017; Isen et al., 2017) and those studying the winter heating system in China (e.g., Chen et al., 2013; Ebenstein et al., 2017; Ito and Zhang, 2020).

Researchers also explore various events and economic shocks (that affect local pollution but are plausibly uncorrelated with unobservable determinants of the outcome) to identify the pollution impact. For example, Schlenker and Walker (2016) use airplane network delays to instrument air pollution levels in the U.S. In the Chinese context, He et al. (2016) leverage changes in air pollution induced by the 2008 Beijing Olympic Games for identifications. The literature has also used economic cycles and trade shocks (e.g., Chay and Greenstone 2003) to generate exogenous variation in local air pollution.

\subsection{Air Pollution and Physical Health}

The impact of air pollution on human health has been widely recognized, with some estimates suggesting that seven million deaths around the world can be attributed to air pollution each year. Indeed, around 90 percent of the people worldwide are breathing air that is deemed harmful to human health. ${ }^{13}$ The majority of them live in countries such as China and India, where particulate pollution can be five to ten times higher than what the World Health Organization (WHO) considers safe.

Mortality Impact from Short-term Exposure. Mortality is arguably the most important health outcome. In the literature, several studies, while focusing on different empirical settings, consistently show that air pollution can significantly increase premature deaths in China.

\footnotetext{
${ }^{13}$ https://www.who.int/phe/publications/en/
} 
In an investigation of China's acid rain policies, Tanaka (2015) finds that infant mortality significantly decreased in regions where $\mathrm{SO}_{2}$ emissions are tightly controlled. Focusing on pollution changes during the 2008 Beijing Olympic Games, He et al. (2016) estimate that a 10 percent decrease in $\mathrm{PM}_{10}$ concentrations reduces the monthly standardized all-cause mortality rate by 8 percent. Bombardini and Li (2020) focus on trade-induced pollution and find that China's export expansion affects infant mortality through pollution concentrations, with a one standard deviation increase in the pollution content of export shock increasing infant mortality by 4.1 deaths per thousand live births.

More recently, as better air quality data have become available, more studies focus on finer measures of air pollution, such as $\mathrm{PM}_{2.5}$ and Air Quality Index (AQI). Fan et al. (2020) exploit the variation in the exact dates when the coal-fired winter heating system is turned on across cities and estimate that a 10-point increase in the AQI as a result of the winter heating leads to a 2.2 percent increase in mortality. He et al. (2020) examine farmers' straw burning practices and find that agricultural fires increase pollution and lead people to die prematurely from cardiorespiratory diseases. They estimate that a $10 \mu \mathrm{g} / \mathrm{m}^{3}$ increase in straw-fire-induced $\mathrm{PM}_{2.5}$ increases the mortality rate by 3.25 percent. The estimated effect in Fan et al. (2020) is similar in magnitude to that in He et al. (2020), but substantially smaller than the estimate in He et al. (2016). A plausible explanation for this difference is that He et al. (2016) use air pollution data from 2006 to 2010, which is a period when reported air pollution concentrations were manipulated such that they were lower than the true concentrations (Greenstone et al., 2020).

Mortality Impact from Sustained Exposure. The aforementioned studies all investigate the pollution effect for a relatively short period of time (e.g., weekly, monthly, or at most annually). Sustained pollution exposure is believed to cause greater damage to human health and is generally the focus of regulation. However, credible evidence on air pollution's long-term impacts is limited both in China and elsewhere.

Estimating the long-term impacts requires researchers to address several empirical challenges, including identifying exogenous long-run variation in air pollution, collecting data on individuals' lifetime exposure to pollution, and finding a strategy to limit compensatory migration in response to air pollution differences. For example, richer people may move into areas with better air quality. Because these people may also have healthier lifestyles and better access to quality medical services, it is difficult to isolate the impact of air pollution from other factors. Oppositely, it is also possible that sicker people are more likely to move to areas with lower air pollution, leading to selection in another direction.

To the best of our knowledge, the first quasi-experimental evidence on the impacts of sustained exposure to air pollution focuses on China. It is characterized by two unique features. First, China's central winter heating system, which dates to China's planning period, provided free winter heating for decades to people living north of the Huai River and forbade winter heating to the south. ${ }^{14}$ Since the winter heating was generated from small coal boilers with few environmental controls, it significantly raised air pollution levels in northern China. Second, China's household registration (Hukou) system has historically controlled migration across cities.

\footnotetext{
${ }^{14}$ Specifically, the Chinese government limited the implementation of the policy started from 1950's to those living north of the Huai River and the Qin Mountains.
} 
The migration restriction means that before internal migration began in earnest, it is possible to know individuals' lifetime exposure to pollution from their current residence. Further, the Hukou system, particularly prior to the 2000 s, prevented most people from engaging in compensatory migration in response to local environmental quality. ${ }^{15}$

Exploiting a regression discontinuity design based on the distance to the Huai River, Chen et al. (2013) and Ebenstein et al. (2017) examine the impact of sustained pollution exposure on life expectancy. The main difference between the two is that Chen et al. (2013) use mortality and pollution data from the 1990s while Ebenstein et al. (2017) use more recent and comprehensive data covering the 2004-2012 period. Both studies find that sustained exposure to air pollution significantly reduced life expectancy. In particular, Ebenstein et al. (2017) estimate that the winter heating policy raised $\mathrm{PM}_{10}$ levels by 46 percent in the region north of the Huai River, which caused a loss of life expectancy of 3.4 years. That implies a $10 \mu \mathrm{g} / \mathrm{m}^{3}$ increase in $\mathrm{PM}_{10}$ levels shortens people's life by 0.64 years.

Morbidity Impact. In addition to the consequence of air pollution on mortality and life expectancy, air pollution is also found to significantly increase morbidity. Different from epidemiological studies that generally focus on the correlation of pollution with the incidence of specific diseases, economic studies give greater emphasis on causality and measuring economic costs associated with morbidity. Barwick et al. (2018) offer perhaps the most comprehensive analysis of the morbidity costs of air pollution. Leveraging air pollution variation caused by wind patterns to examine $\mathrm{PM}_{2.5}$ concentrations, the authors find that annual reduction in national healthcare spending from complying with the WHO's annual standard of $10 \mu \mathrm{g} / \mathrm{m}^{3}$ would amount to $\$ 42$ billion, or nearly 7 percent of China's total healthcare spending in 2015 .

Several other studies assess the morbidity impact of air pollution in a particular region, or for a subpopulation in China. Zhong et al. (2017) leverage Beijing's driving restrictions that affect the number of vehicles on the road to estimate the impact of pollution on morbidity. They find that traffic congestion caused by driving restrictions lead to worse air pollution and a higher demand for ambulance services. Chen et al. (2018) use thermal inversion as the instrument and examine the effects of air pollution on the health status of students in Guangzhou city. They collect detailed records of school attendance and disease records from more than 3,000 schools and detect a sizable effect of air pollution on school attendance caused by respiratory diseases. Using data from international schools in north China, Liu and Salvo (2018) also find air pollution significantly increases student absences.

Pollution Spillovers. A related line of research examines the spillover effect of China's pollution on neighboring regions. Jia and $\mathrm{Ku}$ (2019) find that South Korea would have had 2,400 fewer cardiorespiratory deaths if China's AQI had been 12 points lower during 2001-2010. The identification is based on Asian dust, a meteorological phenomenon whereby yellow dust clouds (and pollutants) pass from China to South Korea by westerly winds. Cheung et al. (2020) show transboundary air pollution from mainland China's manufacturing hub increases air pollution in Hong Kong, which further causes more people to die from cardiorespiratory diseases.

\footnotetext{
${ }^{15}$ The policy has been loosened in recent years. Ebenstein et al. (2017) assessed migration patterns, and they discovered that migration did not appreciably alter people's lifetime exposure to air pollution.
} 


\subsection{Air Pollution, Mental Health, Happiness, and Cognitive Ability}

Mental disorders are the second leading contributors to the global disease burden, accounting for 7 to 13 percent of disability-adjusted life-years (Vigo et al., 2016). Medical and epidemiological research has also documented that air pollutants (particularly particulate matter) can lead to brain base oxidative stress and inflammation, impairing brain function, and exacerbating depression and anxiety (e.g., Sørensen et al., 2003).

Chen et al. (2018), Xue et al. (2019), and Zheng et al. (2019) are among the first to assess how air pollution affects mental health and happiness in China. ${ }^{16}$ Both Chen et al. (2018) and Xue et al. (2019) use nationally representative data from the China Family Panel Studies (CFPS), in which individuals self-report their mental health along many dimensions. Chen et al. (2018) use data from 2014 to 2015 and leverage thermal inversions to instrument local air quality; Xue et al. (2019) use data from 2010 to 2014 and rely on fixed effects models to identify the pollution impact. Both studies find that exposure to higher levels of $\mathrm{PM}_{2.5}$ increases the probability of a self-reported mental illness, confirming the epidemiological link between air pollution and mental health. However, the estimated effects of the two studies differ in size, with the estimates of Chen et al. (2018) substantially larger than those of Xue et al. (2019). Zheng et al. (2019) analyze the sentiment in the contents of 210 million geotagged tweets on Chinese social media and find that air pollution is negatively associated with happiness in urban China.

Studies also show that air pollution can affect people's cognition and decision-making processes. Zhang et al. (2018) analyze the relationship between air pollution and individuals' cognitive performance in verbal and math tests using the CFPS data. They find that long-term exposure to air pollution impedes people's cognitive performance, and the effects can be more pronounced as people age. Chang et al. (2018) examine individuals' decisions to purchase and cancel health insurance in China. They find that elevated pollution increases the number of health insurance contracts sold on that day, but conditional on purchase and better air quality during the coolingoff period (i.e., cost-free cancellation) induces more cancellations of the insurance contracts. Chew et al. (2019) conduct lab experiments in 2012 and find that high $\mathrm{PM}_{2.5}$ levels lead to increased risk aversion to gains, risk tolerance over losses, and ambiguity aversion over gains; and to greater impatience in temporal discounting.

Relatedly, using data from the financial market, two recent studies show that air pollution affects financial decision-making. Specifically, Li et al. (2019) show that air pollution (measured using city-level air quality index) significantly increases the disposition effects of investors and argues that mood regulation provides a potential mechanism. Rui et al. (2019) find that poor air quality during corporate site visits by investment analysts is associated with lower earning forecast relative to realized earning. The authors attribute this finding to pollution-induced pessimism.

\subsection{Air Pollution and Productivity}

\footnotetext{
${ }^{16} \mathrm{We}$ focus on research that uses nationally representative data from China because studies that use data from local areas tend to generate mixed results.
} 
Thanks to the availability of high-frequency production data in the past few years, a growing literature examines the impact of air pollution on the productivity of Chinese workers. Manufacturing jobs are usually labor-intensive and require workers to be physically healthy. To study the manufacturing workers' productivity loss due to air pollution, He et al. (2019) assemble daily worker-level output data from two Chinese firms in the textile industry. Exploiting day-to-day changes in air quality, they show that the current-day impact of air pollution on worker productivity is largely negligible, while prolonged exposure to air pollution has a modest impact on output. Specifically, a $10 \mu \mathrm{g} / \mathrm{m}^{3}$ increase in $\mathrm{PM}_{2.5}$ concentrations sustained over 25 days would only reduce daily output by one percent.

Chang et al. (2019) investigate workers in the service sector. Compared with manufacturing jobs, service-oriented positions are more cognitively demanding; this kind of work reflects the nature of employment for a larger share of workers in modern economies. Using daily performance data of workers in two call centers in China, the authors estimate that a 10-unit increase in the Air Pollution Index (API) decreases the number of daily calls handled by a worker by 0.35 percent. The negative impact of air pollution on the number of calls is primarily driven by workers taking longer breaks between calls, not by them spending more time in answering calls. The estimated effect in Chang et al. (2019) is similar in magnitude to that found by He et al. (2019).

Though call center work relies largely on mental rather than physical skills, such work is not particularly difficult to master. Kahn and Li (2020) focus on elite workers - judges working in the government - and examine how air pollution affects their productivity. The authors find that increases in $\mathrm{PM}_{2.5}$ could significantly prolong the "decision time" to rule on a given case (i.e., how much time a judge takes to adjudicate a case after it has been assigned), an important metric of judges' productivity.

Graff Zivin et al. (2019) study the performance of high school students during high-stakes exams. The identification relies on pollution variation caused by straw burning and wind. Using data from the National College Entrance Examination during the period from 2005 to 2011, they find that straw burning leads to worse exam performance; a one-standard-deviation increase in the difference between upwind and downwind straw burning during the exam decreases the total exam score by 1.42 percent of a standard deviation (or 0.6 of a point).

While the studies discussed above shed light on the relationship between air pollution and contemporaneous productivity, their representativeness and long-term validity is less clear because they focus on specific lines of work and specific sectors. Using a nationally representative sample of all Chinese manufacturing firms from 1998 to 2007, Fu et al. (2019) estimates the effect of air pollution effect on productivity. Their identification strategy relies on short-run variation in air pollution due to thermal inversions and estimates that a $10 \mu \mathrm{g} / \mathrm{m}^{3}$ decrease in $\mathrm{PM}_{2.5}$ increases productivity by 8.2 percent. This estimate is an order of magnitude larger than previous estimates from Chang et al. (2019) and He et al. (2019) that rely on shortterm changes in air pollution. Using the Huai River winter heating regression discontinuity design, Ebenstein and Greenstone (2020) find that childhood exposure to air pollution leads to reduced educational attainment and lower wages as an adult. 
Overall, recent studies using data from China point to the negative impact of air pollution on labor productivity. Yet, the magnitude of the impact of the effect size varies greatly across different studies. Given the important implications of these findings in evaluating the benefits and costs of air quality improvements, further research is needed to better understand the impact heterogeneity. That being said, the accumulating evidence suggests that if we only focus on health outcomes, the full costs of air pollution can be potentially greatly understated.

\subsection{Impacts of Water Pollution}

Most studies of environmental pollution focus on air pollution, partly because air quality data are readily available in many places. In comparison, relatively few studies examine water pollution because systematic data on water pollution are rare. As for China, even though its surface water system was severely degraded, many people in rural areas still rely on surface water for daily use, including drinking.

Ebenstein (2012) is among the first to estimate the impact of surface water pollution on health. Using rainfall as the instrument, he finds that a one-grade decrease (on a six-grade scale) in surface water pollution increases the digestive cancer death rate by 9.7 percent. He and Perloff (2016) also focus on the omnibus water grade as the water quality measure to examine the impact of surface water pollution on infant mortality. They find that surface water pollution has a non-monotonic effect on infant mortality: as water quality degrades, infant mortality first goes up and then goes down.

Lai (2017) studies the impacts of exposure to pollution in drinking water by comparing the outcomes for people who drink surface water and groundwater in regions with different intensities of rice pesticide use. The study takes advantage of changes in the intensity of pesticide use that occurred in 2004, starting from which China shifted from taxing agriculture to subsidizing agricultural programs. Using a disability index as a measure of health, he finds that increased use of pesticides adversely affects health outcomes of rural residents 65 and older.

A parallel line of research focuses on the impacts of clean drinking water. While these studies do not directly measure the degree of water pollution, they all suggest that clean drinking water brings about massive health benefits. Using village-level data, Zhang (2012) shows that introducing piped water into villages improves the health status for both adults and children. In a similar setting, Zhang and Xu (2016) investigate China's rural drinking water program and find that providing clean drinking water to children will increase their educational attainment in the long run. Fan and He (2019) examine the impact of piped water connection on infant mortality. They instrument piped water coverage using the minimum-cost paths between water sources and different counties and show that piped water provision significantly reduced infant mortality.

\section{Compensatory Responses to Pollution}

Facing high levels of pollution, individuals can take preventive measures to reduce exposure and mitigate the impact. These risk-compensating behaviors include avoidance actions and defensive spending in the short run, and household sorting in the long run. Initial empirical evidence on avoidance behavior has been based on data from the U.S. (e.g., Neidell 2009). Research on 
avoidance behavior using data from China is only a recent effort. As the compensatory responses are costly, they are part of air pollution's social costs. In this section, we first discuss the role of pollution information in fostering behavioral changes, then summarize findings on how people protect themselves against pollution in China.

\subsection{Pollution Information}

Avoidance behaviors rely critically on whether people have access to accurate pollution information and their awareness of the potential health impacts. The lack of high-quality pollution information and low awareness of the air pollution impact may hinder effective defensive behavior, especially among the poor and less educated (Greenstone and Jack 2015; Hausman and Stolper 2020). Before 2013, public access to real-time pollution measures was absent in most Chinese cities. The MEE (formally the MEP, Ministry of Environmental Protection) began compiling the Air Pollution Index (API) for major cities in 2000 and gradually expanded the network. The MEE initially did not control the monitoring stations. Instead, local environmental bureaus, whose leaders were appointed by local governments, gathered and reported the data. Research has found evidence of manipulation of the API data in many cities (e.g., Andrews, 2008; Ghanem and Zhang, 2014; Greenstone et al., 2020).

The real-time pollution monitoring and disclosure program (henceforth, the information program) was launched in 2013. It marked a turning point in pollution information access and awareness. The central government installed more than 1,600 U.S. EPA-grade monitoring stations, each equipped with automated, real-time monitoring devices that track concentrations for six criteria pollutants. In about two years, the monitoring network had managed to cover the entire nation. The central government also established a parallel data streaming system - one in which in situ monitoring results stream in real time to city-, province- and central-level governments.

Greenstone et al. (2020) argue that the nature of the automation of the information program has the potential to address the principal-agent problem in China's environmental monitoring, where the central government is the principal who wants accurate information and pollution reduction, and local officials are the agents who tend to hide such information because they place a greater emphasis on economic growth. The authors find that automated monitoring significantly improved the quality of China's air pollution data and that the post-automation trends from the real-time monitoring data are close to those from satellite-derived pollution measures. The study also finds that the availability of accurate pollution information in the wake of the new information program has led to more avoidance behaviors, as measured by online searches for air filters and face masks.

Barwick et al. (2019) document the profound impacts of the information program by exploiting rich data on a wide array of outcomes - including pollution awareness, short- and long-run economic activities, and health outcomes. Using an event-study design based on the staggered introduction of the information program, the authors show that the program transformed the landscape of public access to pollution information and dramatically increased households' awareness about pollution issues. These changes triggered a cascade of short-run and long-run behavioral changes in household activities, including increases in online searches for pollutionrelated topics, adjustments in day-to-day consumption patterns to avoid pollution exposure, and 
higher WTP for housing in less polluted areas. As a result of both short- and long-term behavioral changes, the program reduced the mortality cost of air pollution by flattening out the dose-response function of pollution on mortality.

Improved information access and awareness of the issue could change household WTP for clear air. For example, Ito and Zhang (2020) find that the WTP estimate based on air purifier sales is much larger after 2013 when the information program started to roll out. Tu et al. (2020) examine the impact of "Under the Dome," a high-profile documentary about China's air pollution released in February 2015. Using a longitudinal survey conducted in the city of Nanjing and exploiting a regression discontinuity (in time) design, the study shows that household WTP for clean air increased among those who had viewed the documentary.

\subsection{Avoidance Behavior and Defensive Investments}

In addition to the aforementioned studies that explicitly examine the consequences of pollution information provision, many studies also examine how changes in pollution levels affect avoidance behaviors.

Sun et al. (2017) analyse the relationship between daily air pollution and the sales of face masks and air purifiers. Using sales indices for face masks and air purifiers from China's largest ecomment platform, Taobao, the authors show that people buy more face masks and air purifiers when ambient pollution levels exceed key alert thresholds; the response is significantly larger among the high-income group. Zhang and Mu (2018) quantify the monetary values of people's investment in face masks by using online sales data from Taobao and exploiting day-to-day changes in air quality across cities. They estimate that a 10-point increase in the AQI increases the consumption of all masks by 5.5 percent, and the consumption of anti-PM $\mathrm{PM}_{2.5}$ masks by 7.1 percent. The findings imply that if China could eliminate 10 percent of heavy pollution days, the total savings on face masks alone would be approximately $\$ 187$ million in China. Relatedly, Barwick et al. (2018) show that elevated $\mathrm{PM}_{2.5}$ levels are positively associated with increased spending on healthcare but reduce spending in supermarkets. Barwick et al. (2019) show that the reduction in consumption is stronger in deferrable categories (such as purchasing daily necessities and eating at restaurants), and weaker for scheduled or less-deferrable categories (such as paying bills, business-to-business transactions, and appointments at cancer treatment centers). Sun et al. (2019) find similar results in that they document a positive correlation between air quality and daily consumption activities in restaurants and shopping malls, based on information from a consumer review platform for restaurants and mobile phone positioning data in Beijing.

Ito and Zhang (2020) made an important contribution to this literature by developing a framework to estimate Willingness to Pay (WTP) for clean air using market sales data of air filters. Leveraging long-run pollution variation caused by China's Huai River central winter heating policy, the authors estimate that a household is willing to pay $\$ 13.4$ annually to remove $10 \mu \mathrm{g} / \mathrm{m}^{3}$ of $\mathrm{PM}_{10}$ and $\$ 32.7$ annually to eliminate the increased pollution caused by China's winter heating policy. The authors discuss several reasons why this estimate could be a lower bound estimate of true WTP, including the limited information on pollution levels and consumer awareness on the health impact of air pollution, especially before 2013. 
Several recent studies document intercity trips as a short-term strategy for pollution avoidance in China based on daily data. Chen et al. (2018) use cell phone data to track consumer movement across cities and Cui et al. (2019) use smartphone-cased location data to show that consumers travel from polluted cities to cleaner cities to avoid pollution. By tracing consumer locations based on credit and debit transactions, Barwick et al. (2020) find that improved transportation infrastructure such as high-speed rail and air connections facilitates pollution avoidance through intercity travel. The ability to avoid pollution through behavioral changes has important implications in understanding the social costs of air pollution.

Multiple studies document that income levels are important determinants of people's WTP for clean air (e.g., Sun et al., 2017; Ito and Zhang, 2020). Because richer people can better protect themselves against pollution, it is possible that they can partially mitigate the air pollution effect. In fact, both Fan et al. (2020) and He et al. (2020) find that the impact of air pollution on mortality is greater in low-income areas than that in high-income areas. Relatedly, Cheung et al. (2020) show that the air pollution effect in Hong Kong has significantly decreased in the past two decades, and attribute the reduction to the improvement in the city's medical system. Liu and Salvo (2018) find that air pollution has a small impact on school attendance among highincome children, whose parents and principals are better informed.

In the context of water pollution, He and Perloff (2016) highlight the critical role of avoidance behaviors in mitigating the health damages from consuming dirty water. They argue that when surface water becomes slightly degraded, people do not notice the pollution and continue consuming it; however, as the pollution gets further worse, people notice the pollution, and thus reduce their consumption of surface water. The avoidance behavior helps to explain the nonmonotonic relationship between water pollution and infant mortality in China.

\subsection{Household Sorting}

Households choose where to live (i.e., vote with their feet) either within a city or across different cities based on housing prices and the provision of local amenities such as public goods and environmental quality (Tiebout 1956). There are two common approaches to study the Tiebout sorting with respect to environmental quality. The first one is based on neighborhood-level data (such as census tract). This approach examines the relationship between the changes in population size and changes in environmental quality in a linear regression framework. The second approach examines how households sort across different locations using a discrete choice framework. Both approaches need to address the same identification challenge: unobservables correlated with both household location choices and environmental quality. Unobservables could include spatially delineated amenities and public goods such as school quality, crime rates, access to public transit, and other neighborhood quality measures.

Empirical literature using U.S. data has generally confirmed that households indeed vote with their feet to seek better environmental quality (e.g., Kahn, 2000; Chay and Greenstone 2005; Banzhaf and Walsh, 2008; Greenstone and Gallagher 2008; Sieg et al., 2010; Bayer et al., 2009). ${ }^{17}$ A small but emerging literature also documents household sorting with respect to

\footnotetext{
${ }^{17}$ In addition, a vast literature applies the hedonic framework in the housing market to estimate household willingness to pay for environmental quality improvements (Chay and Greenstone 2005; Greenstone and Gallagher,
} 
environmental quality in China. Chen et al. (2017) examine the impacts of air pollution on crosscity migration in China using the first approach based on population changes measured with the population census. They use thermal inversion as the instrument and find that air pollution significantly affects migration in China, and the effect is driven mostly by well-educated people and young professionals.

Freeman et al. (2019) take the second approach by employing a household-sorting model similar to Bayer et al. (2009). They study household location choices across cities while accounting for moving costs and the potential endogeneity in air quality. Wind directions and large-scale thermal power plants outside the city are used to generate exogenous variation in local air pollution. Their analysis shows that Chinese households take air quality into account in their location decisions, and on average, they would pay about 22 USD for a one-unit reduction in annual $\mathrm{PM}_{2.5}$ concentrations. This estimate is nearly an order of magnitude larger than that from Ito and Zhang (2020). Although both studies use revealed preference approaches, the choices considered and the identification strategies are different, making it difficult to understand the sources of the large difference in these estimates of WTP for air quality.

Households could take more extreme measures, such as migrating to other countries, to avoid persistent and severe pollution, leading to brain drain. Severe air pollution could also hinder foreign direct investment by deterring foreign managers from relocating to China. Qin and Zhu (2018) provide a correlation analysis of China's air pollution and citizens' interest in emigration. Based on a city-by-day online search index as a measure of people's emigration sentiments, they find that if a given day's AQI increases by 100 points, searches on "emigration" grow by anywhere from 2 percent to 5 percent the next day. The effect is more pronounced at higher pollution levels.

Household location choices based on air quality could have important implications on firm productivity and performance, because firms located in more polluted areas may be less able to recruit and retain high-skilled workers. Using thermal inversion as the instrument, Khanna et al. (2019) confirm that pollution affects the spatial distribution of skilled workers and that sorting on pollution leads to productivity loss in polluted cities. Exploiting the exogenous variation in air pollution from China's central heating policy, Xue et al. (2019) find that firms in more polluted areas have less non-locally born executives and that the education level of their top executives and employees is lower on average. They show that this negatively affects firm performance, with stronger negative impacts evident among firms that more heavily rely on human capital in their production.

\section{Concluding Remarks and Future Research}

Developing countries, especially the fast-growing economies that rely heavily on manufacturing and fossil fuels, face the world's most severe pollution challenges. China's recent experiences are without historical precedent, both in terms of the speed with which the quality and availability of information on pollution have increased and the rapidity of the decline in air pollution concentrations. Further, China's ambition to lower air pollution has only become more

2008; Currie et al., 2015; Muehlenbachs et al., 2015). Household location choices based on environmental quality is a key underlying channel of the hedonic framework. 
intense in recent years. ${ }^{18}$ Given the rich spatial and temporal variation in pollution and environmental policies in the country, and the increased availability of fine-scale data on social and economic activities, we believe there is much to learn from China's experiences.

This review provides a summary of the existing scholarly work that looks into the consequences of environmental pollution and this literature is poised to become even richer in the future. These studies have already deepened our understanding of environmental issues in China, which will be important for other developing countries as well. Some of the research findings have started to generate policy impacts. For example, after the Chinese government learned that the coal-fired winter heating system had brought about disastrous health consequences, it launched a largescale clean energy programs that is replacing coal with natural gas as the heating fuel. ${ }^{19}$ As China continues to combat pollution, we expect that research in this area has a high potential to contribute to the adoption of evidence-based environmental policymaking in China.

We conclude this review by pointing out several important directions for future research. First, we believe that understanding the consequences of sustained pollution exposure remains the most important question both for research and policy. However, most existing studies focus on the short and medium run variation in pollution for opportunistic reasons. Future research should prioritize identifying long-run quasi-experimental, or even experimental variation in pollution.

Second, existing studies show that the negative impacts of pollution extend beyond the direct health consequences, and there is an urgent need for research on how air pollution influences long-run human capital acquisition, human cognition, and productivity. The knowledge accumulated so far has suggested that the present health-focused enumerations of pollution costs may significantly underestimate the true costs of pollution (e.g., Ebenstein and Greenstone 2020). Besides, the extent to which compensatory behavior (e.g., avoidance expenditure, sorting, etc.) can mitigate the negative impact of pollution remains largely under-explored.

Third, the estimated impacts of pollution on some key outcomes can vary greatly across different studies, likely driven by differences in the sample coverage, identification strategies, and time horizons, etc. However, we know very little about what factors are more important in explaining the discrepancies and which estimates should be regarded as more credible. This inconsistency imposes a challenge for the research community in their communications with policymakers and the public. Future research is warranted to try to understand the source of these differences.

Fourth, research on the causes and consequences of water pollution, and the available policy options, is less advanced than work on air pollution. The impact of water quality matters a great deal not only to human health but also to ecosystem services. Water pollution has different dynamics and spatial patterns from air pollution due to the differences in pollution sources and the nature of spillovers. Despite the improvement in air quality and surface water quality, groundwater quality has degraded in the past decade, which is concerning given that groundwater is the primary drinking water source in many parts of the country.

\footnotetext{
${ }^{18}$ According to the Atmospheric Pollution Prevention and Control Law (2018 Amendment), all the governments at and above the county level should include air pollution prevention and control in their economic and social development planning and design concrete plans to reach the environmental quality standards by 2025 .

${ }^{19}$ See for example: https:/www.chinadialogue.net/article/show/single/ch/10285-Three-year-cut-to-life-expectancyfrom-coal-heating-
} 
Fifth, practically no economic research addresses soil pollution in China. Soil pollution, primarily from industrial factories and farming practices, could pose dangers to human health, not only to local residents but to consumers of food products from the affected area. Anecdotal evidence suggests that soil pollution could be a widespread issue in China (Sun et al., 2019), yet public discussion has largely neglected this threat. Systematic data collection in this area would be an essential first step to understand and address this challenge. Similarly, plastic pollution is an increasing concern for wildlife as plastic production and usage increase over time and plastic waste flows into the ocean and enters natural habitats (Chu et al., 2020).

As China's environmental policies evolve and data access expands, there is a continuing opportunity for the world to learn from China's practices. We have little doubt that when the next literature review is written, we will have a much deeper understanding of the complex linkages between human well-being and environmental quality and how government policies can influence these relationships.

\section{References:}

Andrews, Steven. 2008. Inconsistencies in Air Quality Metrics: 'Blue Sky' Days and PM10 Concentrations in Beijing. Environmental Research Letters 3(3): 034009.

Arceo, Eva, Rema Hanna, and Paulina Oliva. 2016. Does the Effect of Pollution on Infant Mortality Differ Between Developing and Developed Countries? Evidence from Mexico City. Economic Journal 126(591): 257-280.

Archsmith, James, Anthony Heyes, and Soodeh Saberian. 2018. Air Quality and Error Quantity: Pollution and Performance in a High-skilled, Quality-focused Occupation. Journal of the Association of Environmental and Resource Economists 5(4): 827-863.

Auffhammer, Maximilian, Min Wang, Lunyu Xie, and Jintao Xu. 2020. The Development of Renewable Electricity Generation in China. Working Paper.

Banzhaf, H. Spencer, and Randall P. Walsh. 2008. Do people vote with their feet? An empirical test of Tiebout. American Economic Review 98(3): 843-63.

Barwick, Panle Jia, Dave Donaldson, Shanjun Li, Yatang Lin, and Deyu Rao. 2020. The Great Getaway: Improved Transportation Networks Facilitate Adaptation to Pollution and Temperature Extremes. Working Paper.

Barwick, Panle Jia, Shanjun Li, Liguo Lin, and Eric Zou. 2019. From Fog to Smog: The Value of Pollution Information. NBER Working paper.

Barwick, Panle Jia, Shanjun Li, Deyu Rao, and Nahim Bin Zahur. 2018. The Morbidity Cost of Air Pollution: Evidence from Consumer Spending in China. NBER Working Paper.

Bayer, Patrick, Nathaniel Keohane, and Christopher Timmins. 2009. Migration and Hedonic Valuation: The Case of Air Quality. Journal of Environmental Economics and Management 58(1): 1-14.

Bishop, Kelly C, Jonathan D. Ketcham, and Nicolai V. Kuminoff. 2019. Hazed and Confused: The Effect of Air Pollution on Dementia., NBER Working Paper.

Bombardini, Matilde, and Bingjing Li. 2020. Trade, Pollution and Mortality in China. Journal of International Economics, 103321.

Chang, Tom Y., Wei Huang, and Yongxiang Wang. 2018. Something in the Air: Pollution and the Demand for Health Insurance. Review of Economic Studies 85(3): 1609-1634. 
Chang, Tom Y., Joshua Graff Zivin, Tal Gross, and Matthew Neidell. 2016. Particulate Pollution and the Productivity of Pear Packers. American Economic Journal: Economic Policy 8(3): 141-169.

Chang, Tom Y., Joshua Graff Zivin, Tal Gross, and Matthew Neidell. 2019. The Effect of Pollution on Worker Productivity: Evidence from Call Center Workers in China. American Economic Journal: Applied Economics 11(1): 151-172.

Chay, Kenneth Y., and Michael Greenstone. 2003. The Impact of Air Pollution on Infant Mortality: Evidence from Geographic Variation in Pollution Shocks Induced by a Recession. Quarterly Journal of Economics 118(3): 1121-1167.

Chay, Kenneth Y., and Michael Greenstone. 2005. Does Air Quality Matter? Evidence from the Housing Market. Journal of Political Economy 113(2): 376-424.

Chen, Bin, Yimeng Song, Tingting Jiang, Ziyue Chen, Bo Huang, and Bing Xu. 2018. RealTime Estimation of Population Exposure to $\mathrm{PM}_{2.5}$ Using Mobile-and Station-Based Big Data. International Journal of Environmental Research and Public Health 15(4): 573.

Chen, Shuai, Paulina Oliva, and Peng Zhang. 2017. The Effect of Air Pollution on Migration: Evidence from China. NBER Working Paper.

Chen, Siyu, Chongshan Guo, and Xinfei Huang. 2018. Air Pollution, Student Health, and School Absences: Evidence from China. Journal of Environmental Economics and Management 92: 465-497.

Chen, Yuyu, Ginger Zhe Jin, Naresh Kumar, and Guang Shi. 2012. Gaming in Air Pollution Data? Lessons from China. The B.E. Journal of Economic Analysis \& Policy (Advances) 13(3).

Chen, Yuyu, Avraham Ebenstein, Michael Greenstone, and Hongbin Li. 2013. Evidence on the Impact of Sustained Exposure to Air Pollution on Life Expectancy from China's Huai River Policy. Proceedings of the National Academy of Sciences 110: 12936-12941.

Cheung, Chunwai, Guojun He, and Yuhang Pan. 2020. Mitigating the Air Pollution Effect? The Remarkable Decline in the Pollution-Mortality Relationship in Hong Kong. Journal of Environmental Economics and Management. 102316.

Chew, Soo Hong, Wei Huang and Xun Li. 2019. Does Haze Cloud Decision Making? A Natural Laboratory Experiment. Working Paper.

Chu, Junhong, Haoming Liu, and Alberto Salvo. 2020. Air Pollution as a Determinant ofFood Delivery and Related Plastic Waste, Nature Human Behaviour, forthcoming.

Clay, Karen, Joshua Lewis, and Edson Severnini. 2016. Canary in a Coal Mine: Infant Mortality, Property Values, and Tradeoffs Associated with Mid-20th Century Air Pollution. NBER Working Paper.

Cui, Can, Zhen Wang, Pan He, Shanfeng Yuan, Beibei Niu, Ping Kang, and Chaogui Kang. 2019. Escaping from Pollution: the Effect of Air Quality on Inter-City Population Mobility in China. Environmental Research Letters 14(12): 124025.

Currie, Janet, Lucas Davis, Michael Greenstone, and W. Reed Walker. 2015. Environmental Health Risks and Housing Values: Evidence from 1600 Toxic Plant Openings and Closings. American Economic Review 105(2): 678-709.

Currie, Janet, and W. Reed Walker. 2011. Traffic Congestion and Infant Health: Evidence from E-ZPass," American Economic Journal: Applied Economics 3(1): 65-90.

Deryugina, Tatyana, Garth Heutel, Nolan H. Miller, David Molitor, and Julian Reif. 2019. The Mortality and Medical Costs of Air Pollution: Evidence from Changes in Wind Direction. American Economic Review 109(12): 4178-4219. 
Deschênes, Olivier, Michael Greenstone, and Joseph S. Shapiro. 2017. Defensive Investments and the Demand for Air Quality: Evidence from the NOx Budget Program. American Economic Review 107(10): 2958-2989.

Dong, Rui, Raymond Fisman, YongxiangWang, and Nianhang Xu. 2019. "Air Pollution, Affect, and Forecasting Bias: Evidence from Chinese Financial Analysts." Journal of Financial Economics, forthcoming.

Ebenstein, Avraham. 2012. The Consequences of Industrialization: Evidence from Water Pollution and Digestive Cancers in China. Review of Economics and Statistics 94(1): 186201.

Ebenstein, Avraham and Michael Greenstone. 2020. Childhood Exposure to Particulate Air Pollution, Human Capital Accumulation, and Income: Evidence from China. Working Paper.

Ebenstein, Avraham, Maoyong Fan, Michael Greenstone, Guojun He, and Maigeng Zhou. 2017. New Evidence on the Impact of Sustained Exposure to Air Pollution on Life Expectancy from China's Huai River Policy. Proceedings of the National Academy of Sciences 114(39): 10384-10389.

Ebenstein, Avraham, Victor Lavy, and Sefi Roth. 2016. The Long Run Economic Consequences of High-Stakes Examinations: Evidence from Transitory Variation in Pollution. American Economic Journal: Applied Economics 8(4): 36-65.

Fan, Maoyong, and Guojun He. 2019. The Impact of Clean Water on Infant Mortality: Evidence from China. Working Paper.

Fan, Maoyong, Guojun He, and Maigeng Zhou. 2020. The Winter Choke: Coal-Fired Heating, Air Pollution, and Mortality in China. Journal of Health Economics. 102316.

Freeman, Richard, Wenquan Liang, Ran Song, and Christopher Timmins, 2019. Willingness to Pay for Clean Air in China. Journal of Environmental Economics and Management 94: 188-216.

$\mathrm{Fu}$, Shihe, V. Brian Viard, and Peng Zhang. 2020. Air Pollution and Manufacturing Firm Productivity: Nationwide Estimates for China. Working Paper.

Greenstone, Michael and Justin Gallagher. 2008. Does Hazardous Waste Matter? Evidence from the Housing Market and the Superfund Program. Quarterly Journal of Economics 123(3): 951-1003.

Ghanem, Dalia, and Junjie Zhang. 2014. Effortless Perfection: Do Chinese Cities Manipulate Air Pollution Data? Journal of Environmental Economics and Management 68(2): 203-225.

Graff Zivin, Joshua, Tong Liu, Ying quan Song, Qu Tang, and Peng Zhang. 2019. The Unintended Impacts of Agricultural Fires: Human Capital in China. NBER Working Paper.

Graff Zivin, Joshua and Matthew Neidell. 2012. The Impact of Pollution on Worker Productivity. American Economic Review 102 (7): 3652-3673.

Greenstone Michael and Ted Gayer. 2009. Quasi-Experimental and Experimental Approaches to Environmental Economics. Journal of Environmental Economics and Management 57(1): 21-44..

Greenstone Michael, Guojun He, Ruixue Jia, and Tong Liu. 2020. Can Technology Solve the Principal-Agent Problem? Evidence from China's War on Pollution. Working Paper.

Greenstone, Michael, and Justin Gallagher. 2008. Does Hazardous Waste Matter? Evidence from the Housing Market and the Superfund Program. Quarterly Journal of Economics 123(3): 951-1003.

Greenstone, Michael, and Rema Hanna. 2014. Environmental Regulations, Air and Water Pollution, and Infant Mortality in India. American Economic Review 104 (10): 3038-3072. 
Greenstone, Michael, and B. Kelsey Jack. 2015. Envirodevonomics: A Research Agenda for an Emerging Field. Journal of Economic Literature 53(1): 5-42.

Hausman, Catherine, and Samuel Stolper. 2020. Inequality, Information Failures, and Air Pollution. Working Paper.

He, Guojun, Maoyong Fan, Maigeng Zhou. 2016. The Effect of Air Pollution on Mortality in China: Evidence from the 2008 Beijing Olympic Games. Journal of Environmental Economics and Management 79: 18-39.

He, Guojun, Tong Liu, Maigeng Zhou. 2020. Straw Burning, PM2.5 and Death: Evidence from China. Journal of Development Economics, 102468.

He, Guojun, and Jeffrey M. Perloff. 2019. Surface Water Quality and Infant Mortality in China. Economic Development and Cultural Change 65(1): 119-139.

He, Jiaxiu, Haoming Liu, and Alberto Salvo. 2019. Severe Air Pollution and Labor Productivity: Evidence from Industrial Towns in China. American Economic Journal: Applied Economics 11 (1): 173-201.

Isen, Adam, Maya Rossin-Slater and W. Reed Walker. 2017. Every Breath You Take-Every Dollar You'll Make: The Long-Term Consequences of the Clean Air Act of 1970. Journal of Political Economy 125(3): 849-909.

Ito, Koichiro, and Shuang Zhang. 2020. Willingness to Pay for Clean Air: Evidence from Air Purifier Markets in China. Journal of Political Economy 128 (5): 1627-1672.

Jia, Ruixue, and Hyejin Ku. 2019. Is China's Pollution the Culprit for the Choking of South Korea? Evidence from the Asian Dust. The Economic Journal 129(624): 3154-3188.

Kahn, Matthew E. 2000. Smog Reduction's Impact on California County Growth. Journal of Regional Science 40: 565-582.

Kahn, Matthew E., and Pei Li. 2020. Air pollution lowers high skill public sector worker productivity in China. Environmental Research Letters. 084003

Kahn, Matthew E., Pei Li, and Daxuan Zhao. 2015. Water Pollution Progress at Borders: The Role of Changes in China's Political Promotion Incentives. American Economic Journal: Economic Policy 7 (4): 223-242.

Karplus, Valerie J., Junjie Zhang, and Jinhua Zhao. 2020. Navigating and Evaluating the Labyrinth of Environmental Regulation in China. Working Paper.

Keiser, David, Cathy Kling, and Joseph Shapiro. 2019. The Low but Uncertain Measured Benefits of U.S. Water Quality Policy, Proceedings of the National Academy of Sciences 116(12): 5262-5269.

Keiser, David, and Joseph Shapiro. 2019. Consequences of the Clean Water Act and the Demand for Water Quality. Quarterly Journal of Economics 134(1): 349-396.

Khanna, Gaurav, Wenquan Liang, A. Mushfiq Mobarak, and Ran Song. 2019. The Productivity Consequences of Pollution-Induced Migration in China. Working Paper.

Knittel, Christopher R., Douglas L. Miller, and Nicholas J. Sanders. 2015. Caution, Drivers! Children Present: Traffic, Pollution, and Infant Health. Review of Economics and Statistics 98(2): 350-366.

Lai, Wangyang. 2017. Pesticide Use and Health Outcomes: Evidence from Agricultural Water Pollution in China. Journal of Environmental Economics and Management 86: 93-120.

Li, Jennifer, Massimo Massa, Hong Zhang, and Jian Zhang. 2019. Air pollution, behavioral bias, and the disposition effect in China. Journal of Financial Economics, forthcoming.

Liu, Haoming, and Alberto Salvo. 2018. Severe air pollution and child absences when schools and parents respond. Journal of Environmental Economics and Management 92: 300-330. 
Muehlenbachs, Lucija, Elisheba Spiller, and Christopher Timmins. 2015. The Housing Market Impacts of Shale Gas Development. American Economic Review 105(12): 3633-3659.

Neidell, Matthew. 2009. Information, Avoidance Behavior, and Health: The Effect of Ozone on Asthma Hospitalizations. Journal of Human Resources 44(2): 450-478.

Qin, Yu and Zhu, Hongjia. 2018. Run Away? Air Pollution and Emigration Interests in China. Journal of Population Economics 31: 235-266.

Salvo, Alberto, and Franz M. Geiger. 2014. Reduction in Local Ozone Levels in Urban São Paulo Due to a Shift from Ethanol to Gasoline Use. Nature Geoscience, 7(6):450-458.

Schlenker, Wolfram and W. Reed Walker. 2016. Airports, Air Pollution, and Contemporaneous Health. Review of Economic Studies 83(2): 768-809.

Sieg, Holger, V. Kerry Smith, H. Spencer Banzhaf, and Randy Walsh. 2004. Estimating the General Equilibrium Benefits of Large Changes in Spatially Delineated Public Goods. International Economic Review 45(4): 1047-1077.

Sillman, Sanford (1999). The relation between ozone, NOx and hydrocarbons in urban and polluted rural environments. Atmospheric Environment 33: 1821-1845.

Sørensen, Mette, Bahram Daneshvar, Max Hansen, Lars O. Dragsted, Ole Hertel, Lisbeth Knudsen, and Steffen Loft. 2003. Personal $\mathrm{PM}_{2.5}$ Exposure and Markers of Oxidative Stress in Blood. Environmental Health Perspectives 111(2): 161-166.

Sun, Cong, Matthew E. Kahn, and Siqi Zheng. 2017. Self-Protection Investment Exacerbates Air Pollution Exposure Inequality in Urban China. Ecological Economics 131: 468-474.

Sun, Cong, Siqi Zheng, Jianghao Wang, and Matthew Kahn. 2019. Does clean air increase the demand for the consumer city? Evidence from Beijing. Journal of Regional Science 59, 409-434.

Sun, Yiming, Hong Li, Guanlin Guo, Kirk T. Semple, Kevin C. Jones. 2019. Soil contamination in China: Current priorities, defining background levels and standards for heavy metals. Journal of Environmental Management 251: 109512.

Tanaka, Shinsuke. 2015. Environmental Regulations on Air Pollution in China and Their Impact on Infant Mortality. Journal of Health Economics 42: 90-103.

Tiebout, Charles M. 1956. A Pure Theory of Local Expenditures. Journal of Political Economy 64(5): 416-424.

$\mathrm{Tu}$, Meng, Bing Zhang, Jianhua Xu, and Fangwen Lu. 2020. Mass Media, Information and Demand for Environmental Quality: Evidence from the "Under the Dome". Journal of Development Economics 143: 102402.

van Donkelaar, Aaron et al. 2016. Global Estimates of Fine Particulate Matter Using a Combined Geophysical-Statistical Method with Information from Satellites, Models, and Monitors. Environmental Science \& Technology 50(7): 3762-3772.

Vennemo, Haakon, Kristin Aunan, Henrik Lindhjem, Hans Martin Seip. 2009. Environmental Pollution in China: Status and Trends. Review of Environmental Economics and Policy, 3(2): 209-230.

Vigo, Daniel, Graham Thornicroft, and Rifat Atun. 2016. Estimating the True Global Burden of Mental Illness. The Lancet Psychiatry 3(2): 171-178.

Xue, Shuyu, Bohui Zhang, and Xiaofeng Zhao. 2019. Brain Drain: The Impact of Air Pollution on Firm Performance. Working Paper.

Xue, Tao, Tong Zhu, Yixuan Zheng, and Qiang Zhang. 2019. Declines in Mental Health Associated with Air Pollution and Temperature Variability in China. Nature Communications 10(1): 1-8. 
Zhang, Jing. 2012. The Impact of Water Quality on Health: Evidence from the Drinking Water Infrastructure Program in Rural China. Journal of Health Economics 31(1): 122-134.

Zhang, Jing, and Lixin Colin $\mathrm{Xu}$. The Long-Run Effects of Treated Water on Education: The Rural Drinking Water Program in China. Journal of Development Economics 122: 1-15.

Zhang, Junjie, and Quan Mu. Air Pollution and Defensive Expenditures: Evidence from Particulate-Filtering Facemasks. Journal of Environmental Economics and Management 92: 517-536.

Zheng, Siqi, and Matthew E. Kahn. 2013. Understanding China's Urban Pollution Dynamics. Journal of Economic Literature 51 (3): 731-72.

Zheng, Siqi, Jianghao Wang, Cong Sun, Xiaonan Zhang, and Matthew E. Kahn. 2019. Air pollution lowers Chinese urbanites' expressed happiness on social media. Nature Human Behaviour 3 (3): 237-243.

Zhang, Wei, C-Y. Cynthia Lin Lawell, and Victoria I. Umanskaya. 2017. The Effects of License Plate-Based Driving Restrictions on Air Quality: Theory and Empirical Evidence. Journal of Environmental Economics and Management 82: 181-220.

Zhang, Xin, Xi Chen, and Xiaobo Zhang. 2018. The Impact of Exposure to Air Pollution on Cognitive Performance. Proceedings of the National Academy of Sciences 115(37): 91939197.

Zhong, Nan, Jing Cao, and Yuzhu Wang. 2017. Traffic Congestion, Ambient Air Pollution, and Health: Evidence from Driving Restrictions in Beijing. Journal of the Association of Environmental and Resource Economists 4(3): 821-856. 
(a) National Level by Pollutants

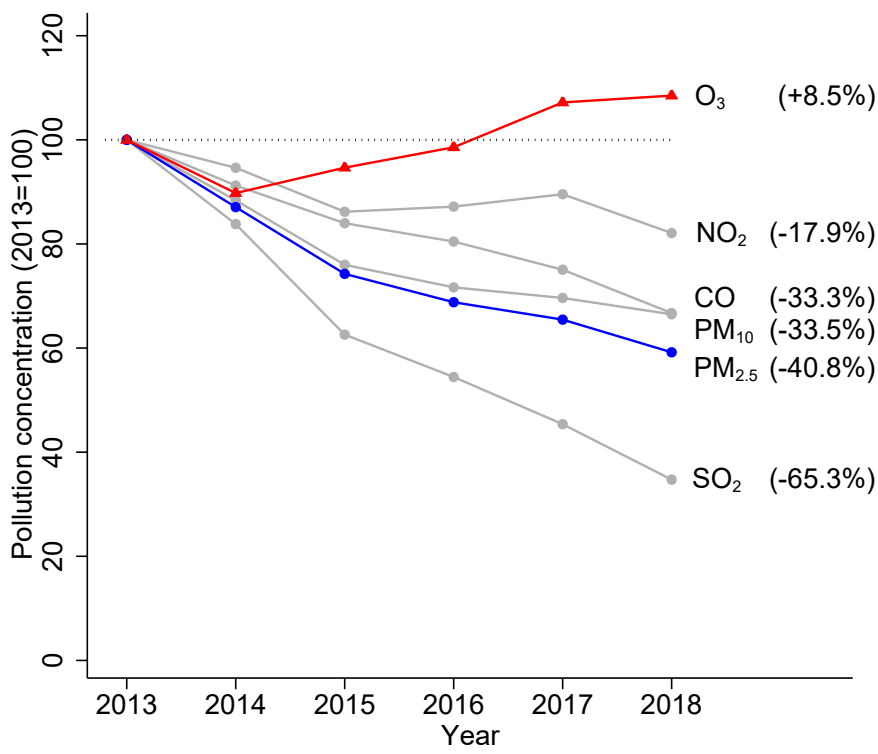

(b) $\mathrm{PM}_{2.5}$ by Region

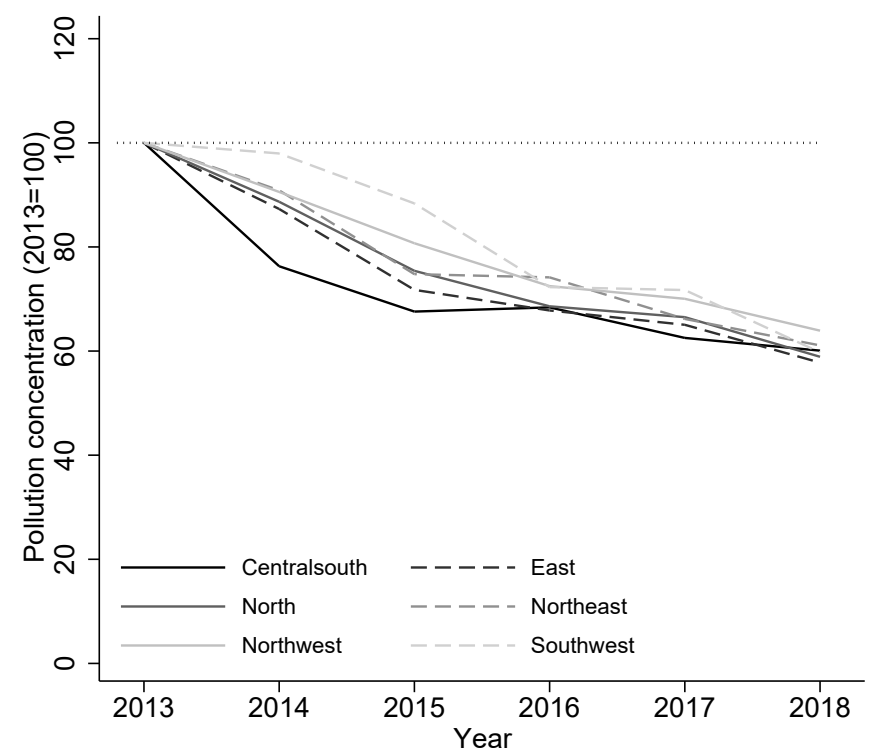

Notes: Panel (a) reports annual concentration of six criteria pollutants. The estimates are obtained from separate OLS regressions of city $\times$ daily pollution concentration on calendar year indicators (omitting 2013) and city fixed effects for each pollutant. Annual values are obtained by adding the regression constant back to the coefficients on the year indicators. Values are normalized to 100 in 2013. Panel (b) reports annual $\mathrm{PM}_{2.5}$ concentration by region. The estimates are obtained from 6 separate OLS regressions (one for each region) of city $\times$ daily $\mathrm{PM}_{2.5}$ concentration on calendar year indicators (omitting 2013) and city fixed effects. Annual values are then obtained by adding the regression constant back to the coefficients on the year indicators.

Figure 2. Trends in Surface Water Quality at Major River Basins, 2010-2018

(a) DO

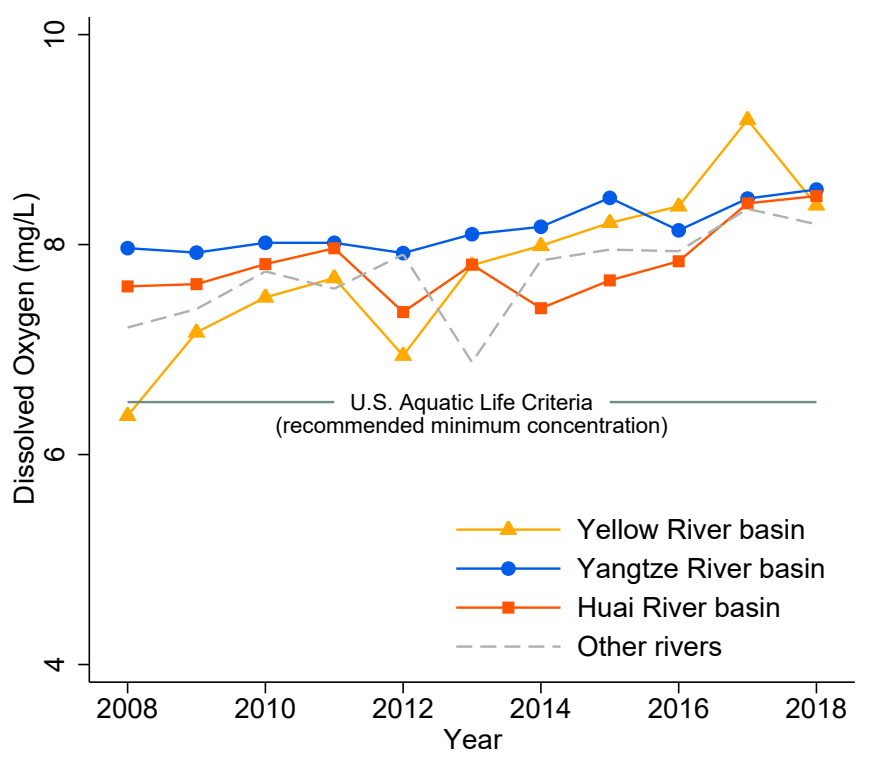

(b) COD

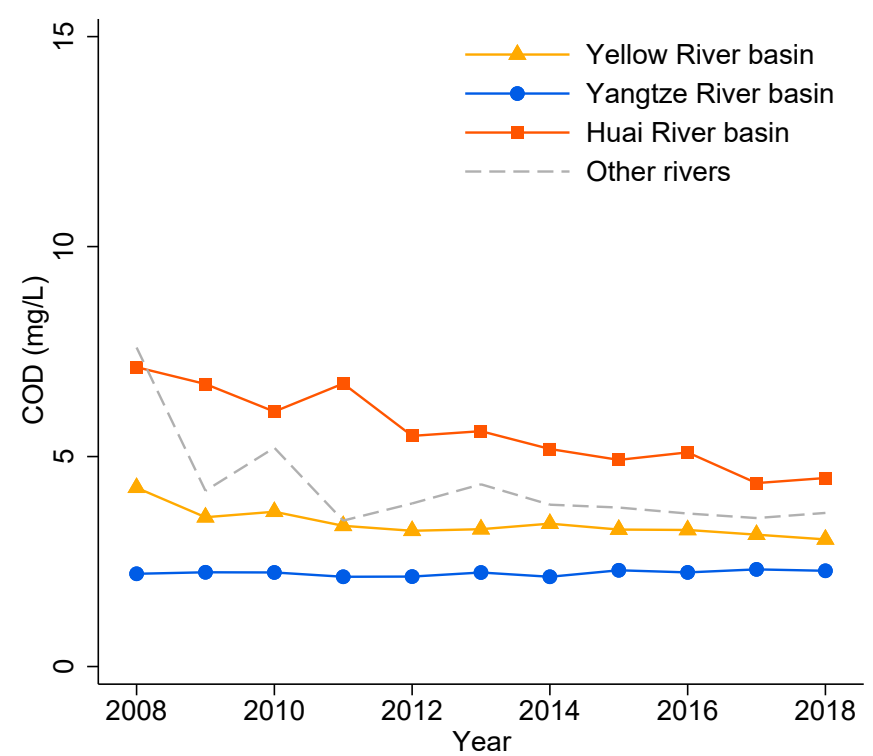

Notes: Panel (a) shows annual average dissolved oxygen concentration (higher is better). The "U.S. Aquatic Life Criteria" (6.5 $\mathrm{mg} / \mathrm{L}$ ) refers to the U.S. EPA Quality Criteria for Water's (1986) recommended 30-day minimum dissolved oxygen concentration criteria for cold water, non-early life stages aquatic lives. Panel (b) shows annual average chemical oxygen demand (lower is better). We excluded the site in Yuncheng (Shanxi Province) where the COD level dropped from 110 to below 20 during the sample period. 


\title{
Appendix
}

\section{China's War on Pollution: Evidence from the First Five Years}

\author{
Michael Greenstone, Guojun He, Shanjun Li, Eric Zou
}

Figure A.1. Concentration of Six Pollutants from Monitoring Stations
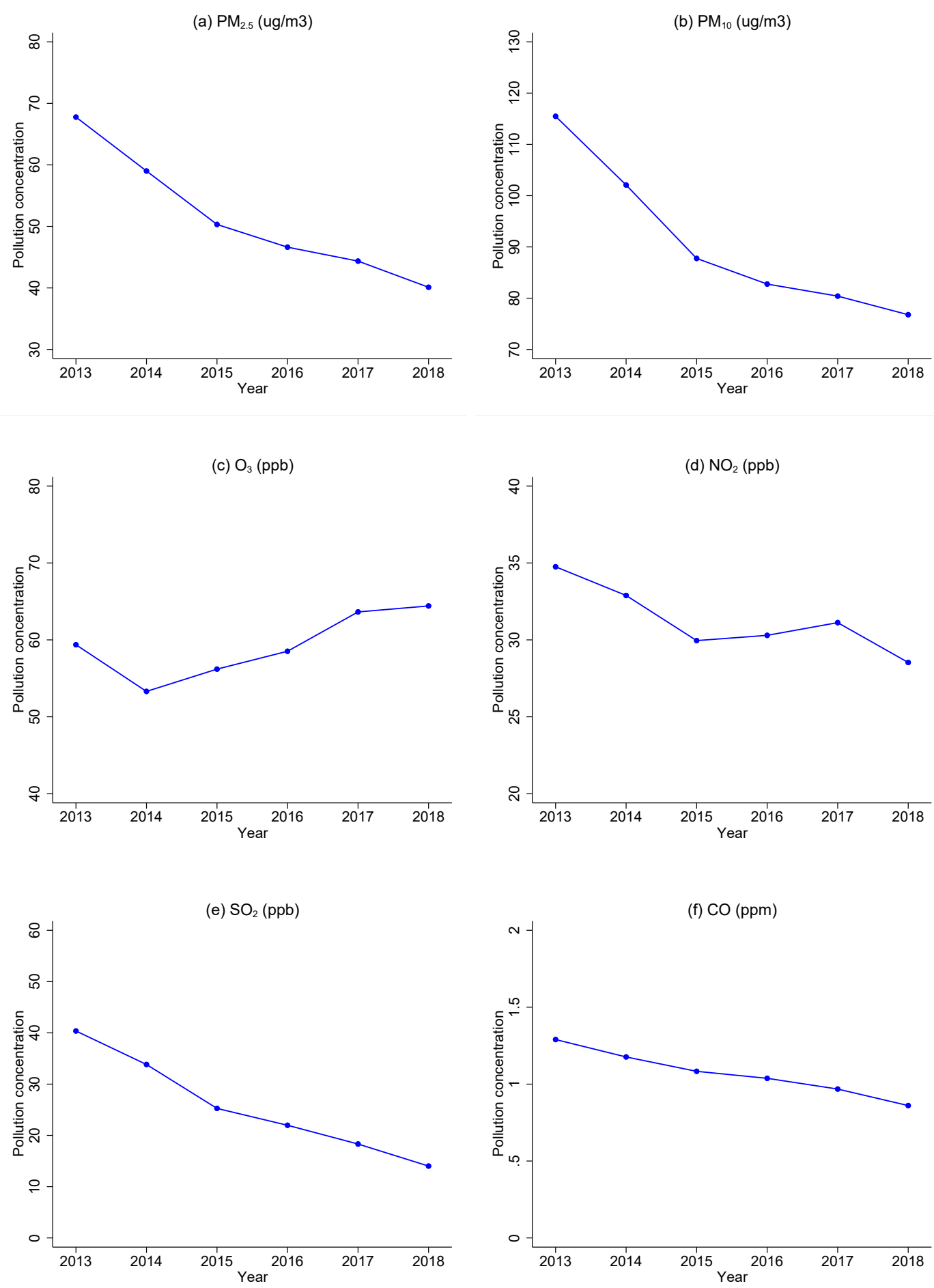

Notes: These graphs report annual concentrations for 6 pollutants average across all monitoring stations. 
Pollution Trends Using Satellite-based Measures Appendix Figure A.2 compares the trends using the $\mathrm{PM}_{2.5}$ data from the real-time pollution monitoring system by China's Ministry of Ecology and Environment (MEE), and the satellite-based estimates based on van Donkelaar et al. (2016). Between 2013 and 2018, $\mathrm{PM}_{2.5}$ levels dropped by $27.7 \mu \mathrm{g} / \mathrm{m}^{3}$, or about 41 percent from 2013 levels. The satellite-based estimates indicate a rise in $\mathrm{PM}_{2.5}$ from 2000 onward, followed by a remarkable drop-off beginning in 2013. Our calculation shows higher levels of $\mathrm{PM}_{2.5}$ from the monitoring data than the satellite-based estimates. We note this could be due to the remaining difference in spatial coverage between the two datasets, and/or uncertainties in both the satellite estimates and ground monitoring data, among other potential explanations. The van Donkelaar et al. (2016) estimates come at a spatial resolution of 10-by-10-km; thus, we cannot calculate levels of $\mathrm{PM}_{2.5}$ at the exact location of the monitors.

A potential concern with government-provided air quality data in China is manipulation (e.g. Ghanem and Zhang 2014). Appendix Figure A.3 presents a week-to-week comparison of the real-time $\mathrm{PM}_{2.5}$ data with independent monitoring by the United States in five major cities: Beijing, Chengdu, Guangzhou, Shanghai, and Shenyang. For all five cities, data provided by the MEE and the U.S. Embassy and consulates match quite well, both for absolute levels and the seasonal patterns of PM2.5. Starting in 2013, both data sources show a clear decline in $\mathrm{PM}_{2.5}$ levels. In Appendix Figure A.4, we have also confirmed that MODIS column Aerosol Optical Depth values - one of the key inputs for measuring particulate pollution in van Donkelaar et al. (2019) - also show a downward trend starting 2013.

Figure A.2. Trends in $\mathrm{PM}_{2.5}$ from Satellite and Motoring Stations

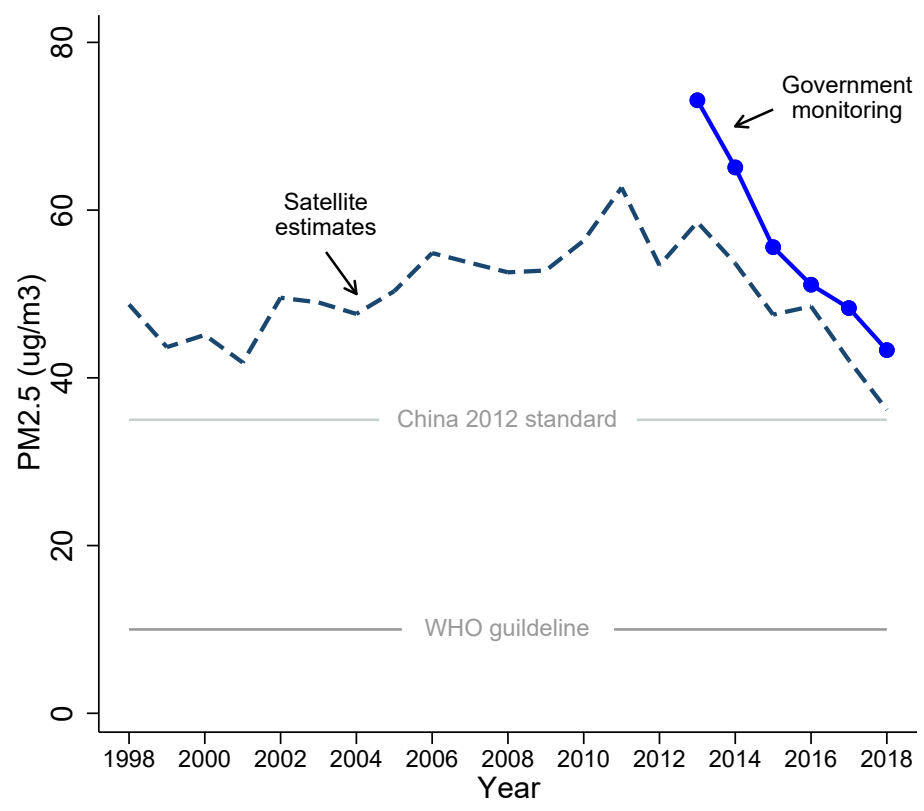

Notes: This graph reports annual $\mathrm{PM}_{2.5}$ concentration. The connected line is $\mathrm{PM}_{2.5}$ trend using the government monitoring data. Estimates are obtained from an OLS regression of city $\times$ daily $\mathrm{PM}_{2.5}$ concentration on calendar year indicators (omitting y2013) and city fixed effects. The values in the graph equal the coefficients on the year indicators plus the regression constant term. The dashed line is $\mathrm{PM}_{2.5}$ trend using satellite-based $\mathrm{PM}_{2.5}$ estimates from Van Donkelaar et al. (2019). In computing this trend, we restrict to a fixed set of grid cells that contain the location of ground monitoring stations as of 2018. "China 2012 standard" refers to The Ambient Air Quality Standards GB 3095-2012 Class-II region standard (residential, industrial, mixed-use, and rural areas). 
Figure A.3. U.S. Embassy versus Government $\mathrm{PM}_{2.5}$ Data

(a) Beijing

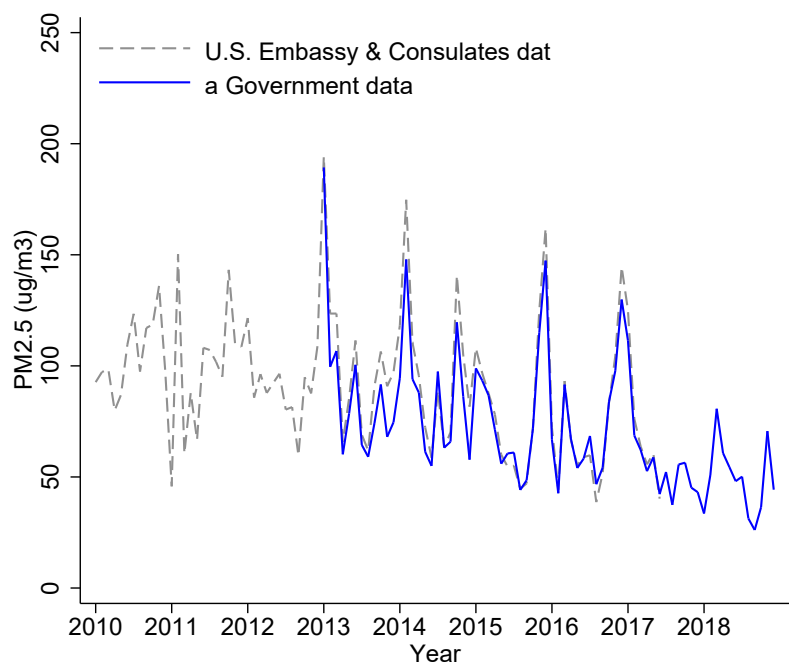

(c) Guangzhou

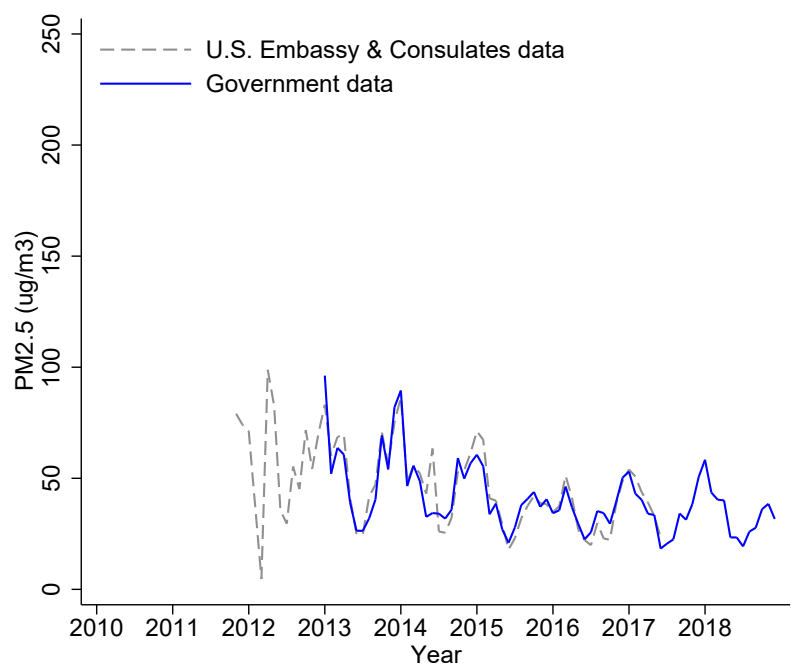

(b) Chengdu

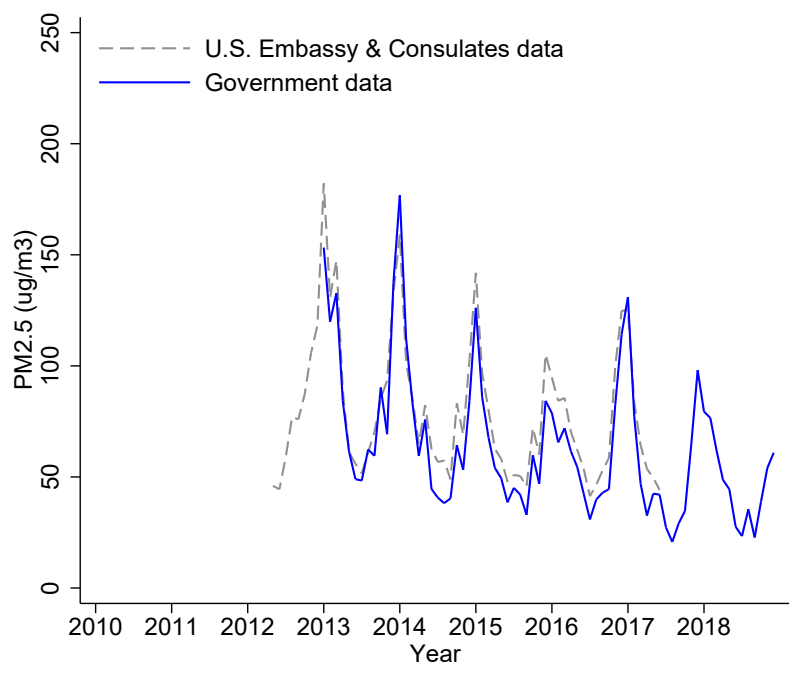

(d) Shanghai

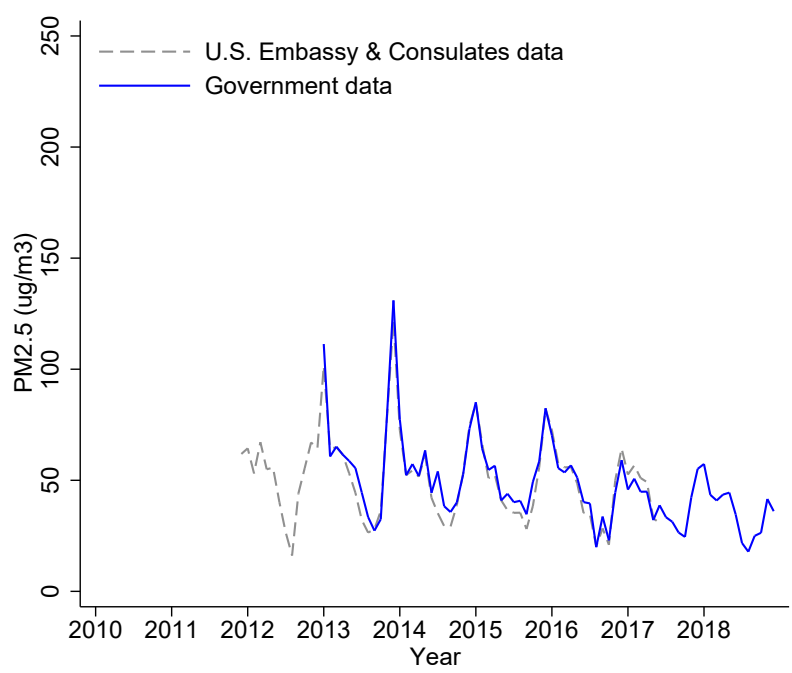

(e) Shenyang

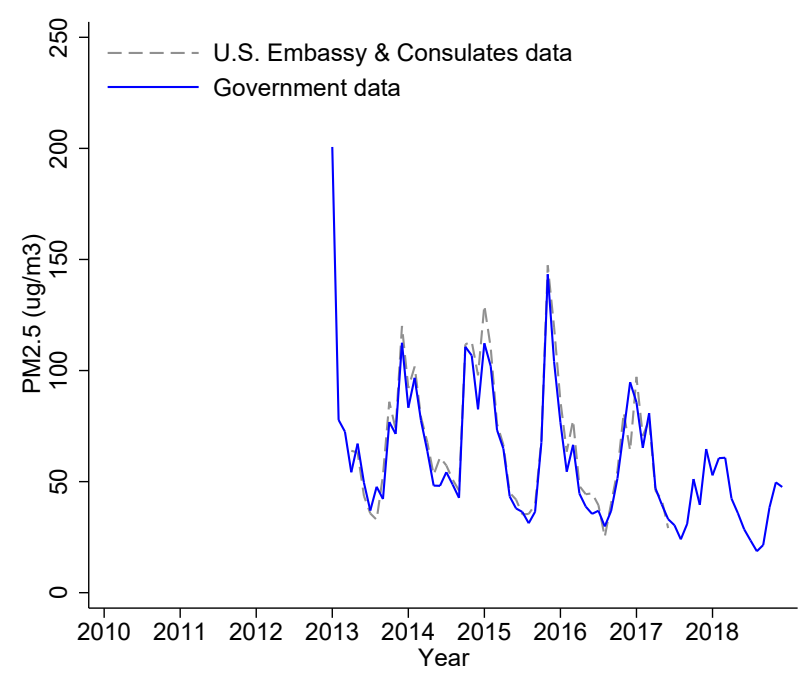

Notes: This graph reports monthly $\mathrm{PM}_{2.5}$ concentrations for 5 cities where $\mathrm{PM}_{2.5}$ monitoring is independently carried out by the U.S. Embassy \& Consulates. 
Figure A.4. Trends in AOD and Satellite-based $\mathrm{PM}_{2.5}$

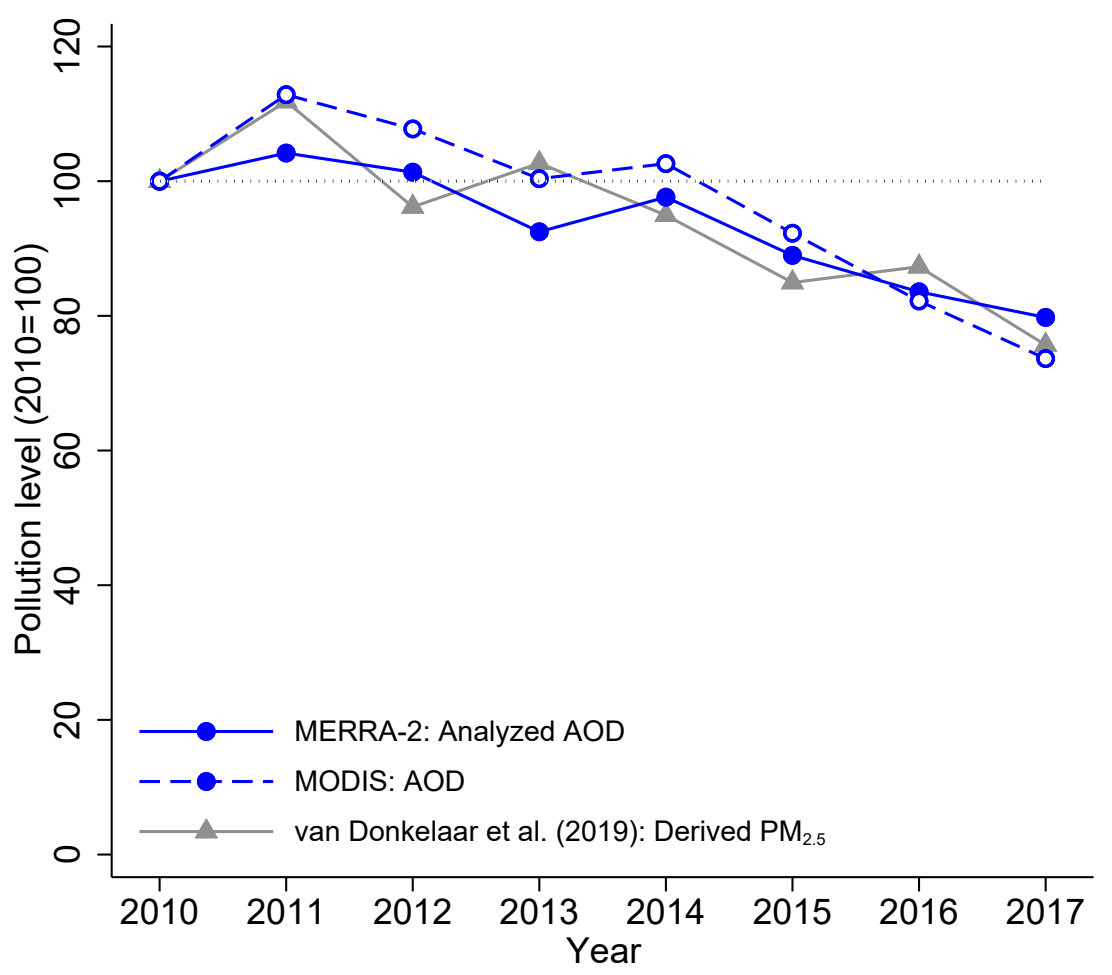

Notes: This graph reports trends in annual AOD measures and satellite-based $\mathrm{PM}_{2.5}$ estimates from Van Donkelaar et al. (2019). The AOD measures are from MERRA-2 and MODIS separately. The trends are based on OLS regression of city $\times$ pollution measures on calendar year indicators (omitting y2013) and city fixed effects. The values in the graph equal the coefficients on the year indicators plus the regression constant term. The figure shows the changes in MERRA-2 and MODIS AOD over time - both based solely on satellite observations - compared with derived PM2.5 which is calibrated to ground monitoring. All three measurements suggest over $23 \%$ reduction in particulates pollution since 2010 . 
Figure A.5. Changes in $\mathrm{PM}_{2.5}$ by City, 2015-2018

(a) Level Change

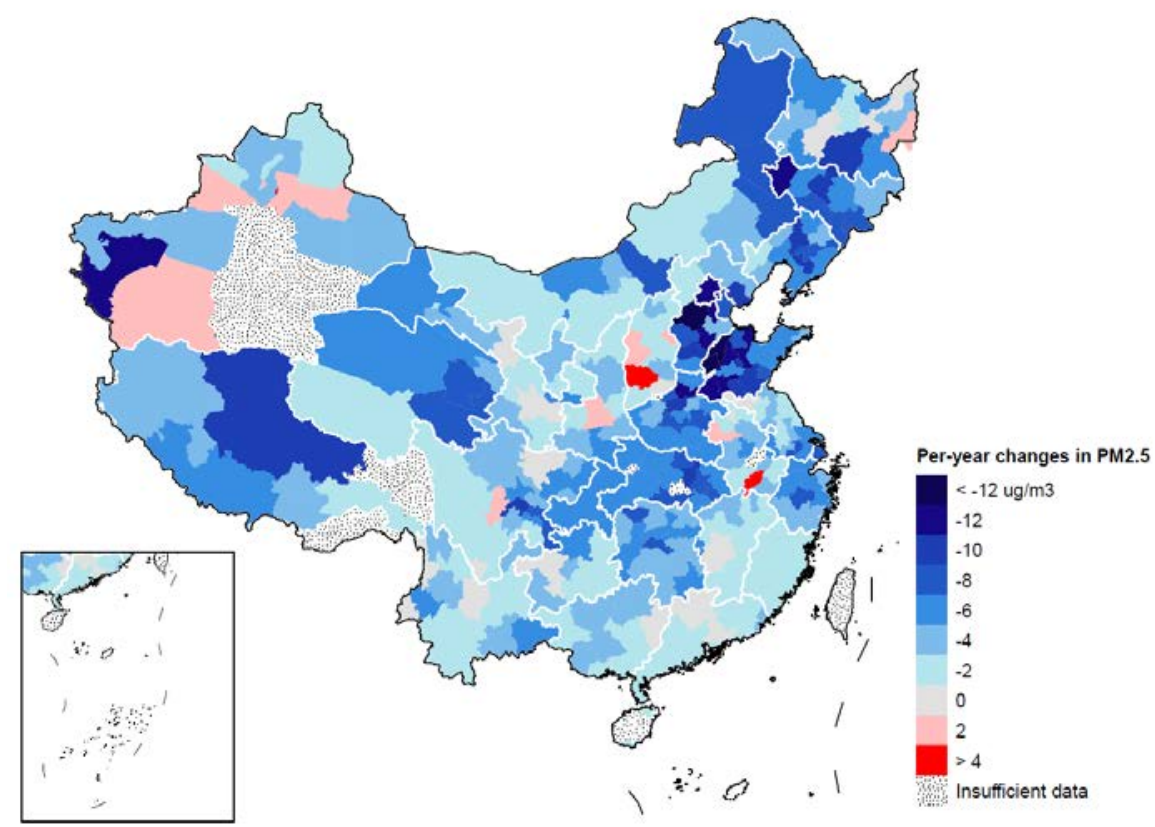

(b) Percentage Change

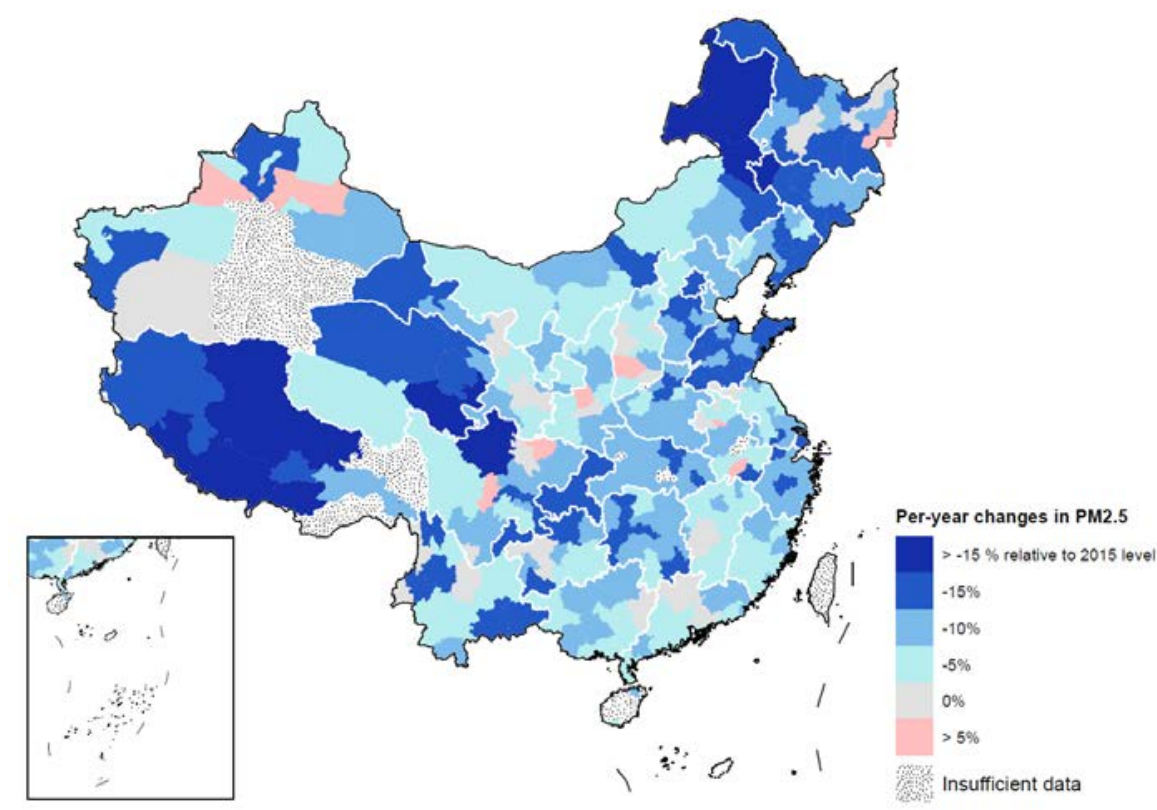

Notes: This maps plot the amount (top) and percentage changes (bottom) of $\mathrm{PM}_{2.5}$ per year for each city between 2015 and 2018. The estimates are obtained from separate OLS regressions (one for each city) of city $\times$ daily $\mathrm{PM}_{2.5}$ concentration on a linear year trend. 
Figure A.6. Correlates of City-Level $\mathrm{PM}_{2.5}$ Reductions

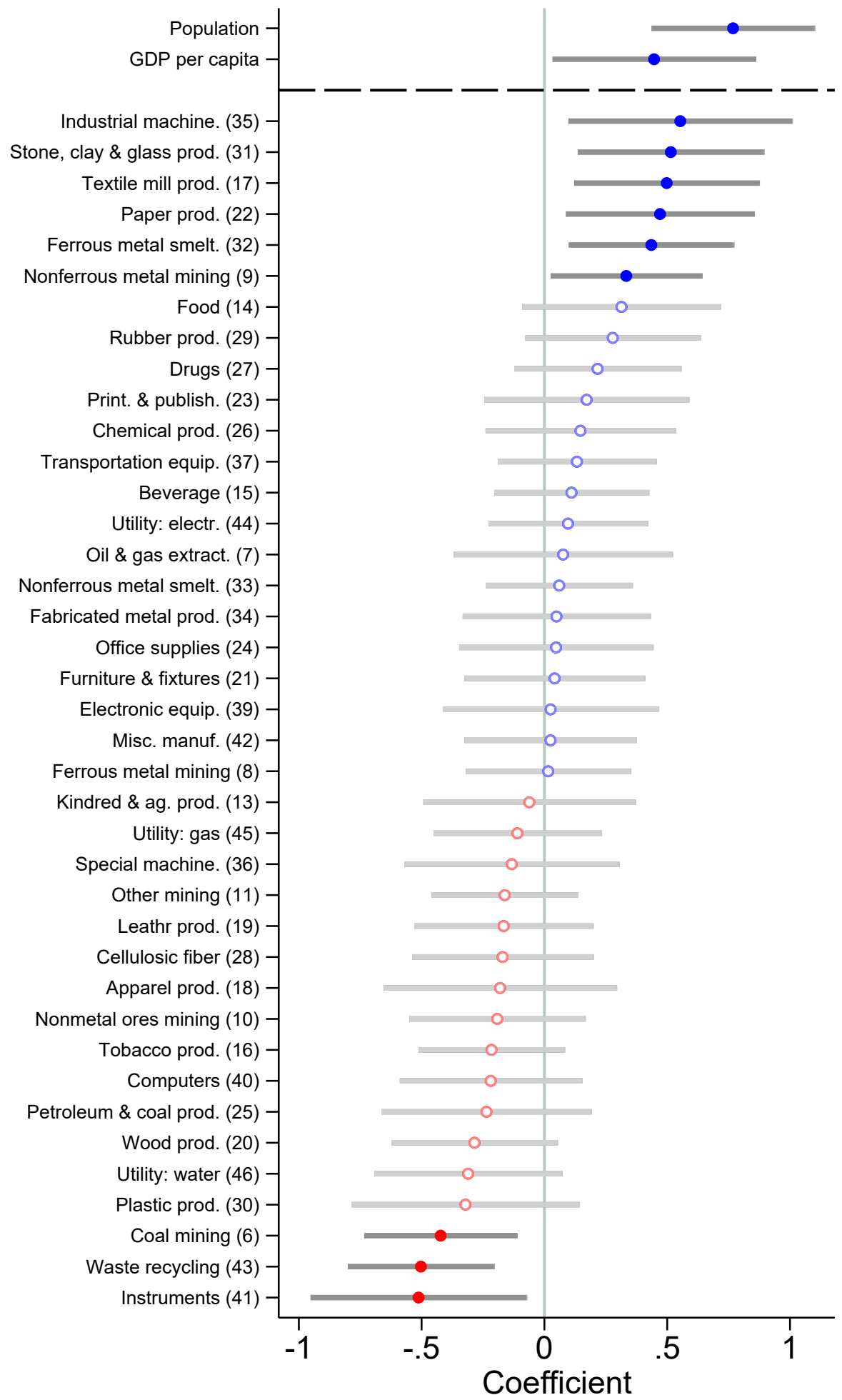

Notes: This graph reports correlates of city-level $\mathrm{PM}_{2.5}$ reduction between 2015 to 2018 . To facilitate comparisons, all explanatory variables are normalized to have zero mean and unit standard deviation. Coefficient estimates from a single cross-sectional regression of city-level $\mathrm{PM}_{2.5}$ reduction per year on z-scores of baseline economic and industrial characteristics . For each 2-digit industry, the industry concentration is measured by the city's y2011-y2012 average industry revenue as a fraction of city's GDP. Solid dots in the graph indicate coefficient estimates that are individually statistically significant at the $5 \%$ level. 
Figure A.7. Correlates of City-Level $\mathrm{PM}_{2.5}$ Reductions in Percentages

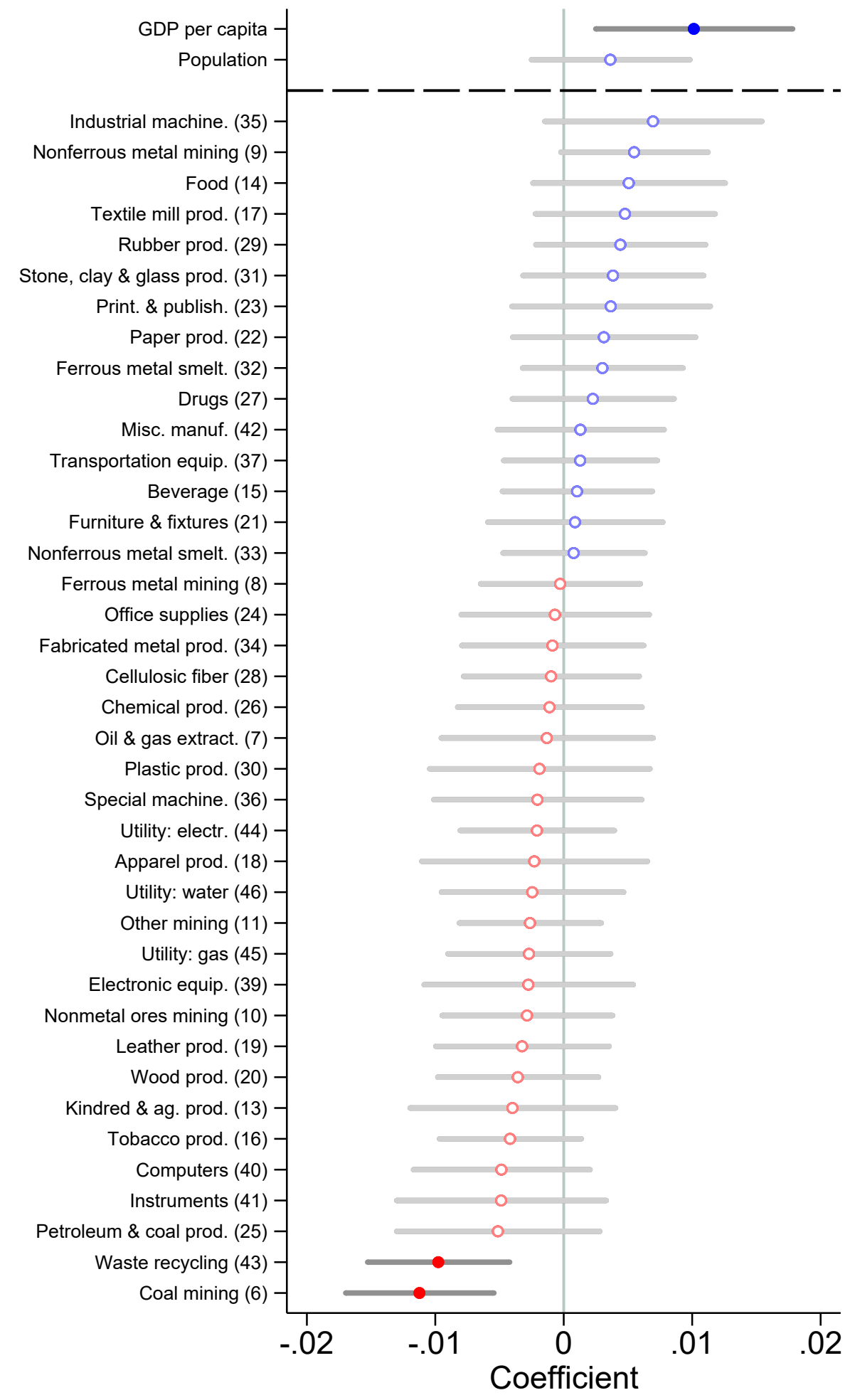

Notes: This graph reports correlates of city-level $\mathrm{PM}_{2.5}$ reduction in pecentages between 2015 to 2018. To facilitate comparisons, all explanatory variables are normalized to have zero mean and unit standard deviation. Coefficient estimates from a single crosssectional regression of city-level $\mathrm{PM}_{2.5}$ reduction per year on z-scores of baseline economic and industrial characteristics . For each 2-digit industry, the industry concentration is measured by the city's y2011-y2012 average industry revenue as a fraction of city's GDP. Solid dots in the graph indicate coefficient estimates that are individually statistically significant at the $5 \%$ level. 
Figure A.8. Trends in Surface Water Quality at Major River Basins, 2010-2018

(a) Location

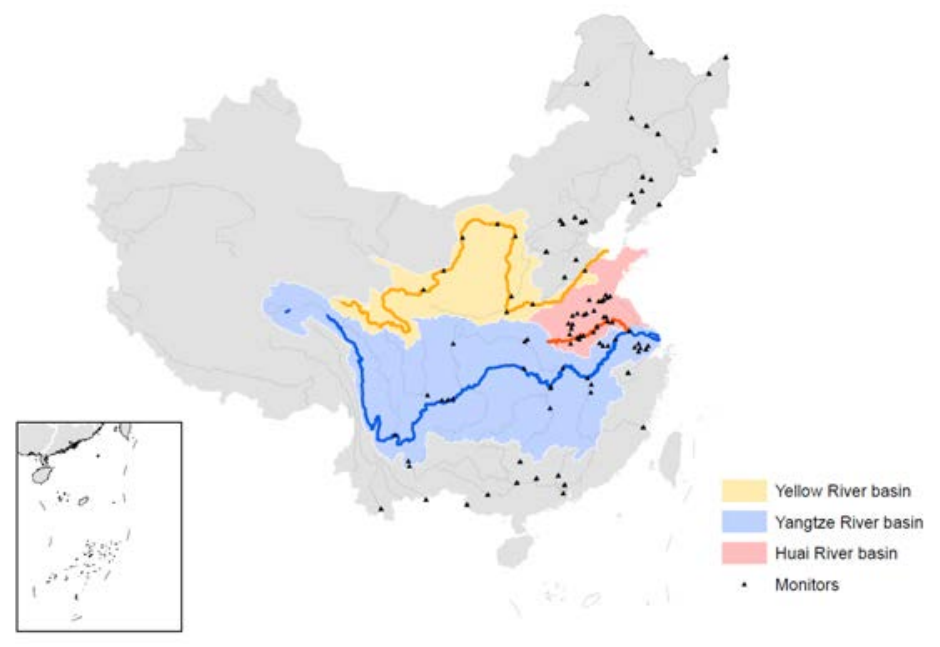

(b) Quality

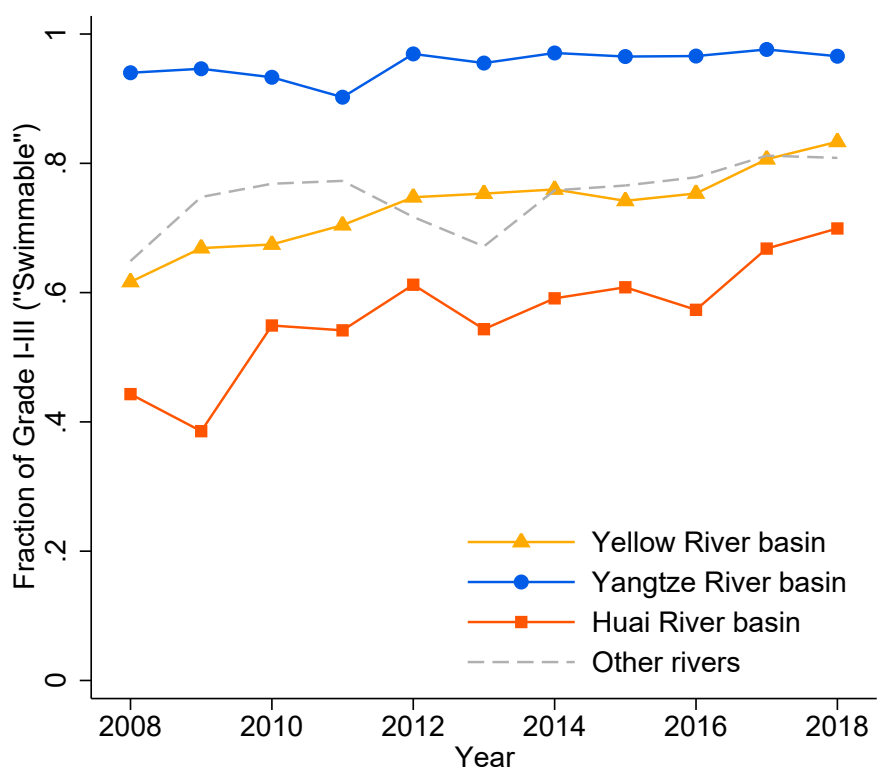

Notes: The map shows the location of the Yellow River basin, the Yangtze River basin, the Huai River basin, and other major rivers. Triangles represent water quality monitoring sites contained in the MEE's Major River Basins Water Quality Weekly Report. The right panel shows fraction of weeks in the year the water quality falls in the GB3838-2020 Grade I, II, and III categories (i.e., better than "swimmable"), averaged across monitors in the corresponding river basin.

Figure A.9. Trends in Ground Water Quality, 2010-2017

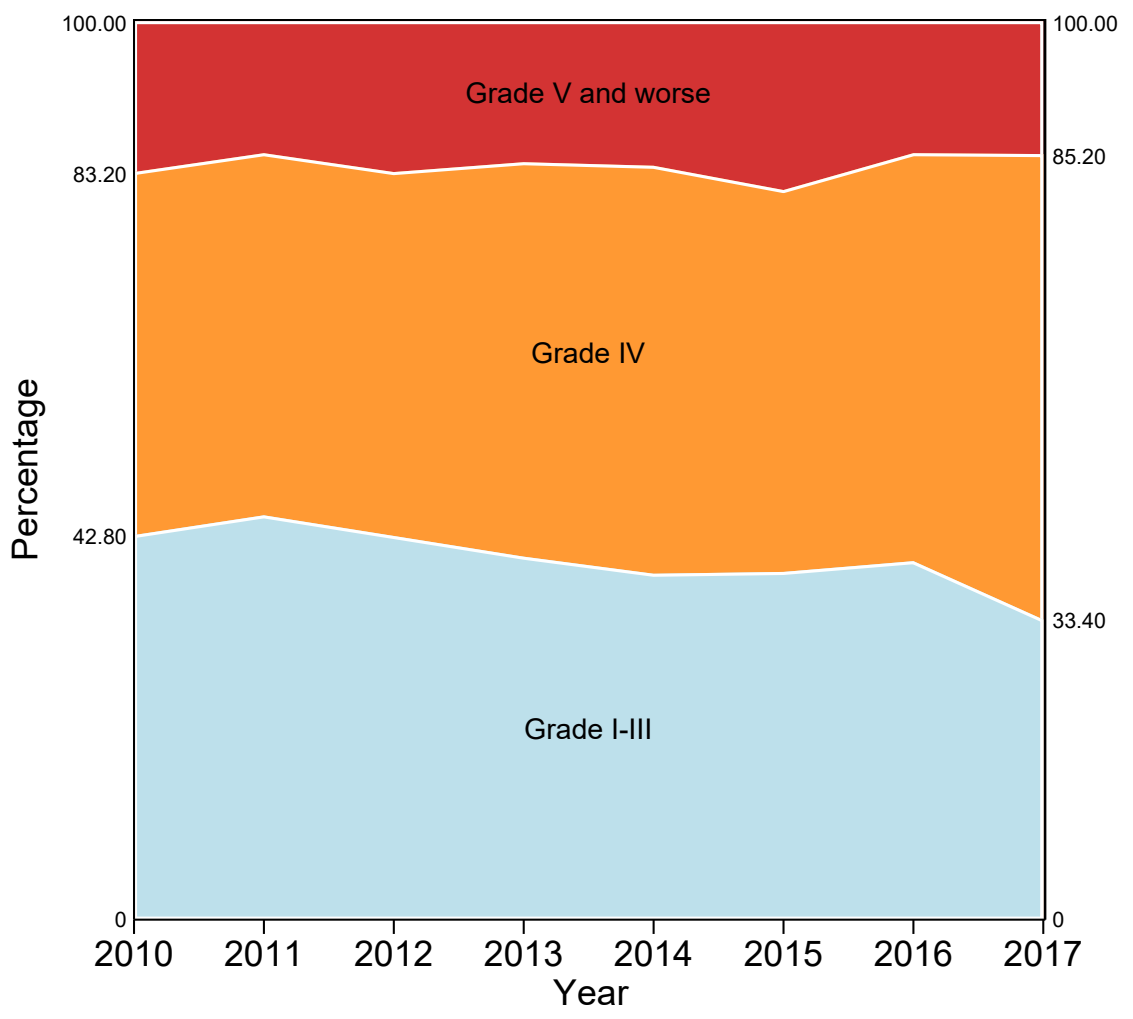

Notes: These statistics are from annual China Water Resources Bulletin. Underlying data are ground water quality sampled from 5,000 wells each year. The graph reports fraction of water samples that falls in the GB/T 14848-2017 Grade I-III ("residential use"), Grade IV ("residential use after treatment"), and Grade V categories ("not for residential use"). 